\title{
Influence of optical errors on the thermal and thermodynamic performance of a solar parabolic trough receiver
}

\author{
Aggrey Mwesigye $^{1 *}$, Zhongjie Huan², Tunde Bello-Ochende ${ }^{3}$, Josua P. Meyer ${ }^{4}$ \\ ${ }^{1}$ School of Mechanical, Industrial and Aeronautical Engineering, University of the Witwatersrand, Johannesburg, \\ Private Bag 3, Wits 2050, Johannesburg, South Africa \\ ${ }^{2}$ Department of Mechanical Engineering, Mechatronics and Industrial Design, Tshwane University of Technology, \\ Private Bag X680, Pretoria, 0001, South Africa. \\ ${ }^{3}$ Department of Mechanical Engineering, University of Cape Town, \\ Private Bag X3, Rondebosch 7701, South Africa. \\ ${ }^{4}$ Department of Mechanical and Aeronautical Engineering, University of Pretoria, \\ Private Bag X20, Hatfield 0028, South Africa.
}

\section{HIGHLIGHTS}

- Effect of optical errors on performance of a parabolic trough receiver is presented.

- Actual heat flux profiles were obtained using Monte Carlo ray tracing and presented.

- Thermal and thermodynamic analysis of the receiver is determined numerically.

- Effect of optical errors on heat flux and temperature distribution is investigated.

- Influence of optical errors on receiver entropy generation rates is presented.

\begin{abstract}
This paper presents results of an investigation covering the influence of optical errors on the thermal and thermodynamic performance of a solar parabolic trough system. The optical performance was evaluated by using Monte Carlo ray tracing for slope errors and specularity errors in the range 0 to $5 \mathrm{mrad}$. A parabolic trough collector (PTC) with a rim angle of $80^{\circ}$ and a concentration ratio of 86 was considered in this study. The heat flux profiles obtained from the
\end{abstract}

\footnotetext{
*Corresponding author Tel.: +27 11717 7378, Fax: +27 117177049

E-mail address: Aggrey.Mwesigye@wits.ac.za
} 
optical analysis were coupled with a computational fluid dynamics tool (ANSYS FLUENT) to numerically investigate the thermal and thermodynamic performance of the receiver. In the numerical analysis, inlet temperatures and Reynolds numbers ranging from $350 \mathrm{~K}-650 \mathrm{~K}$ and 6 800-1 140000 were considered, respectively. Results show that, slope and specularity errors influence the heat flux distribution on the receiver's absorber tube. Results further show that the optical performance and thermal performance reduce significantly as the slope errors increase. For the range of parameters considered, the intercept factor reduces by up to $21 \%$ while the overall thermal efficiency reduces by up to $17 \%$ as optical errors increase. Receiver thermodynamic performance is shown to deteriorate as slope errors increase.

Key words: Entropy generation, optical errors, parabolic trough receiver, thermal performance, thermodynamic performance

\section{Nomenclature}

a Parabolic trough collector aperture width, m

$A_{a} \quad$ Projected collector aperture area, $\mathrm{m}^{2}$

$A_{r} \quad$ Projected absorber tube area, $\mathrm{m}^{2}$

$B e \quad$ Bejan number = entropy generated due to heat transfer/total entropy generated

$C_{1}, C_{2}, C_{\mu}$ Turbulent model constants

$C_{R} \quad$ Concentration ratio

$C_{p} \quad$ Specific heat capacity, $\mathrm{J} \mathrm{kg}^{-1} \mathrm{~K}^{-1}$

$I_{b} \quad$ Direct normal irradiance, $\mathrm{W} \mathrm{m}^{-2}$

$d_{g i} \quad$ Glass cover inner diameter, $\mathrm{m}$ 


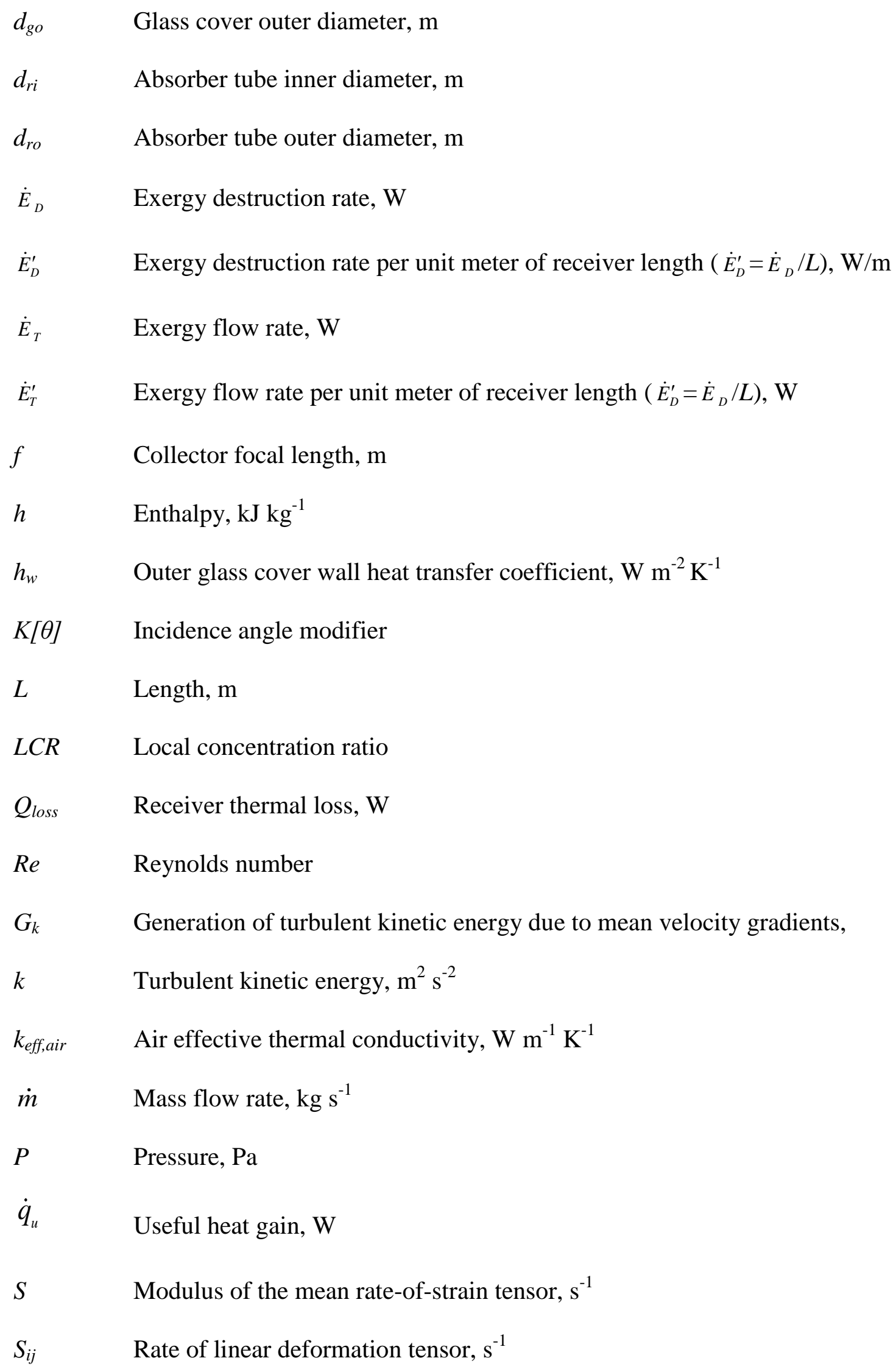




$$
\begin{aligned}
& S_{\text {gen }} \quad \text { Entropy generation rate due to heat transfer and fluid friction in the receiver, } \mathrm{W} \mathrm{K}^{-1} \\
& S_{\text {gen }}^{\prime} \quad \text { Entropy generation per unit length of the receiver, } \mathrm{W} \mathrm{m}^{-1} \mathrm{~K}^{-1} \\
& S^{\prime \prime \prime}{ }_{g e n} \quad \text { Volumetric entropy generation, } \mathrm{W} \mathrm{m}^{-3} \mathrm{~K}^{-1} \\
& S^{\prime \prime \prime}{ }_{g e n, F} \quad \text { Volumetric entropy generation due to fluid friction, } \mathrm{W} \mathrm{m}{ }^{-3} \mathrm{~K}^{-1} \\
& S^{\prime \prime \prime}{ }_{\text {gen }, H} \quad \text { Volumetric entropy generation due to heat transfer, } \mathrm{W} \mathrm{m}{ }^{-3} \mathrm{~K}^{-1} \\
& T \quad \text { Temperature, } \mathrm{K} \\
& u_{i}, u_{j} \quad \text { Velocity components, } \mathrm{m} \mathrm{s}^{-1} \\
& u^{\prime}, v^{\prime}, w^{\prime} \quad \text { Velocity fluctuations, } \mathrm{m} \mathrm{s}^{-1} \\
& u_{\tau} \quad \text { Friction velocity }\left(\mu_{\tau}=\sqrt{\tau_{w} / \rho}\right), \mathrm{m} \mathrm{s}^{-1} \\
& \text { V Volume, } \mathrm{m}^{3} \\
& V_{w} \quad \text { Wind velocity, } \mathrm{m} \mathrm{s}^{-1} \\
& x_{i}, x_{j} \quad \text { Spatial coordinates, } \mathrm{m} \\
& x, y, z \quad \text { Cartesian coordinates } \\
& y^{+} \quad \text { Dimensionless wall coordinate } \\
& -\rho \overline{u_{i}^{\prime} u_{j}^{\prime}} \quad \text { Reynolds stresses, } \mathrm{N} \mathrm{m}^{-2}
\end{aligned}
$$

\section{Greek letters}

$\begin{array}{ll}\alpha & \text { Thermal diffusivity, } \mathrm{m}^{2} \mathrm{~s}^{-1} \\ \alpha_{t} & \text { Turbulent thermal diffusivity, } \mathrm{m}^{2} \mathrm{~s}^{-1} \\ \alpha_{a b s} & \text { Absorber tube absorptivity } \\ \sigma_{h . t} & \quad \text { Turbulent Prandtl number for energy } \\ \sigma_{\varepsilon} & \quad \text { Turbulent Prandtl number for } \varepsilon \\ \sigma_{k} & \text { Turbulent Prandtl number for } k \\ \sigma_{\text {slope }} & \text { Slope error, mrad }\end{array}$




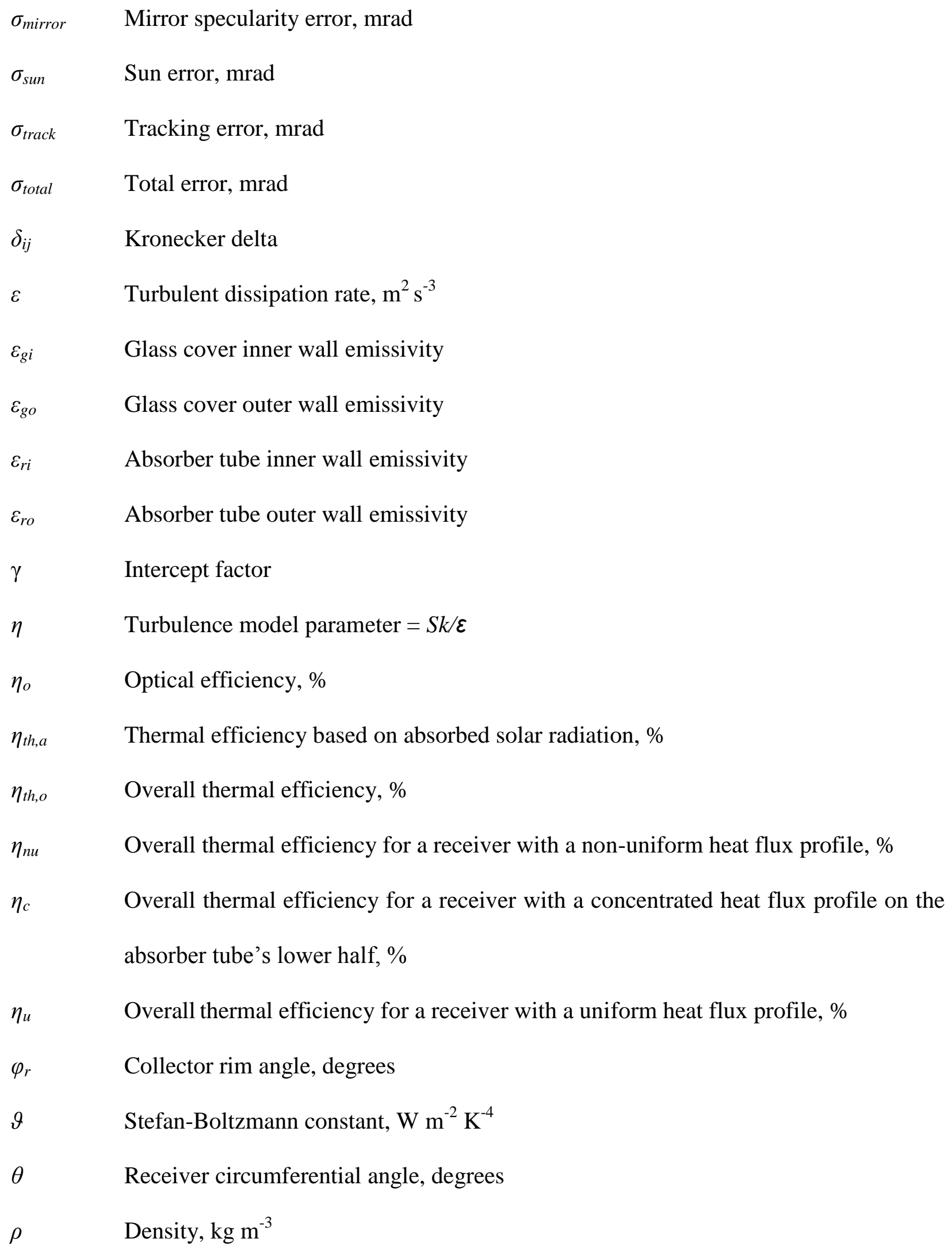




$\begin{array}{ll}\rho_{m} & \text { Mirror reflectivity } \\ \tau_{g} & \text { Glass cover transmissivity } \\ \left(\tau_{g} \alpha_{a b s}\right)_{n} & \text { Effective transmittance-absorptance factor at normal incidence } \\ \lambda & \text { Fluid thermal conductivity, } \mathrm{W} \mathrm{m}^{-1} \mathrm{~K}^{-1} \\ \mu & \text { Viscosity, Pa s } \\ \mu_{t} & \text { Eddy viscosity, Pa s } \\ v & \text { Kinematic viscosity, } \mathrm{m}^{2} \mathrm{~s}^{-1}\end{array}$

\section{Subscripts}

$\begin{array}{ll}\text { gi } & \text { Ambient state } \\ \text { go } & \text { Glass cover inner side } \\ i, j, k & \text { General spatial indices } \\ \text { inlet } & \text { Inlet conditions } \\ \text { outlet } & \text { Outlet conditions } \\ \text { ri } & \text { Absorber tube inner side } \\ \text { ro } & \text { Absorber tube outer side } \\ \text { sky } & \text { Sky conditions } \\ t & \text { Turbulent }\end{array}$

Superscripts

$\begin{array}{ll}- & \text { Time averaged value } \\ \sim & \text { Fluctuation from mean value } \\ \sim & \text { Dimensionless parameter }\end{array}$




\section{Introduction}

With several research and development efforts, the cost of electricity from concentrated solar thermal systems has reduced significantly. The concentrated solar power (CSP) industry has continued to grow steadily since 2009 from an installed capacity of about $0.6 \mathrm{GW}$ to about 3.6 GW by the end of 2013 (IEA, 2014). Most of this CSP capacity is from parabolic trough systems (Richter et al., 2009, IRENA, 2012). This is mainly because parabolic trough solar systems are the most commercially and technically developed technologies for concentrated solar power (Philibert and Frankl, 2010, Price and Kearney, 1999).

Parabolic trough systems consist of a collector, which is a parabolically shaped mirror of high reflectance for collecting incident solar radiation. The solar rays incident on the mirror are reflected and focused onto the receiver tube also called the heat collection element (HCE) and subsequently converted to thermal energy. The receiver is made of a metallic absorber tube that is enclosed in a glass envelope. The space between the tube and the glass cover is evacuated to very low vacuum pressures to minimise receiver convection heat loss (Price et al., 2002, Kalogirou, 2004). The absorber tube is also selectively coated to give it a high absorptance for incoming radiation and low emittance for infrared radiation.

The optical performance of the parabolic trough collector system significantly influences the performance of the entire system. The system's optical performance will determine how many of the rays incident on the collector will be intercepted by the receiver and subsequently the heat flux distribution on the receiver. The optical performance of the collector depends on several factors, which include the geometry of the collector, various materials used in the construction of the system and various errors encountered during the construction and/or operation of the system 
(Güven and Bannerot, 1986). The errors encountered will influence the intercept factor. The intercept factor is defined as the ratio of energy intercepted by the receiver to the energy reflected by the concentrating collector (Güven and Bannerot, 1986). Pottler et al. (2014) suggest that intercept factors in the range $96-99 \%$ are achievable with appropriate collector design, quality components and proper assembly and installation of the collector. In their study, quality control measures to ensure high values of intercept factors are discussed.

The optical efficiency of the parabolic trough collector system is given by Güven and Bannerot (1986) as

$\eta_{o}=[K(\theta)] \rho_{m}\left(\tau_{g} \alpha_{a b s}\right)_{n} b$

The factors affecting the optical efficiency can be clearly identified from Eq. (1). The first bracketed term is the effect of the angle of incidence, the second bracketed term represents the material properties and the last term incorporates all the optical errors. The first term, also known as the incidence angle modifier is applied when the angle of incidence is not zero. In this form, $K(\theta)$ includes all effects of the angle of incidence including cosine losses and end losses. In other studies, these effects of the incidence angle may be considered separately as shown in Hoste and Schuknecht (2015). Moreover, the end losses are dependent on the angle of incidence reducing to zero at an angle of incidence of zero (Hoste and Schuknecht, 2015).

For a fully tracking collector or in cases where the angle of incidence is zero (normal incidence), the incidence angle modifier, $K(\theta)=1$ (Marif et al., 2014, Kalogirou, 2009). Even though full tracking or two-axis tracking parabolic trough systems are highly efficient since the angle of incidence is always zero, their use is limited by their greater mechanical complexity, less rigidity and more auxiliary piping requirements (Fernández-García et.al, 2010). The only two-axis 
collector ever marketed was the Helioman $3 / 32$ by Maschinenfabrik Augsburg-Nümberg (M.A.N.) in Munich (Germany) (Fernández-García et.al, 2010). There are some recent efforts to develop improved two axis systems, for example Bakos (2005) proposed a low cost, low maintenance and easy to operate two-axis sun tracking system for a parabolic trough collector. In another study, Peng et al. (2013) proposed a new rotatable-axis tracking parabolic trough collector in view of improving solar-field efficiency. For purposes of this study and similar to the study by Balghouthi et al. (2014), a simplification of normal incidence was used. Such that material properties and the intercept factor are the major factors determining the optical performance of the parabolic trough system for this case when the angle of incidence is zero.

Gaul and Rabl (1980) presented experimental data as well as analytical expressions for the determination of the incidence angle effects on the performance of a parabolic trough collector. Güven and Bannerot, (1986) give a detailed illustration of the different types of errors that are likely to be encountered in parabolic trough collectors. These include: (1) Material errors which include the specularity of the reflective material, transmissivity of the glass cover and absorptivity of the absorber tube coating. (2) Manufacture and assembly errors which include local slope errors, profile errors, misalignment of the reflector during assembly and mislocation of the receiver tube. (3) Operation errors which include tracking errors, errors due to wind loading and temperature effects, reduced specularity due to dust accumulation, misalignment of the receiver during operation due to sagging of the receiver tube, permanent expansion of the receiver tube and change in location of the effective focus due to increased profile errors. Thomas and Guven (1994) presented analytical results for the determination of the effect of optical errors on heat flux distribution around the absorber tube of a parabolic trough concentrator. 
Several other studies have been carried out to investigate the errors affecting the optical performance of parabolic trough systems (García-Cortés et al., 2012,Lee, 2014,Maccari and Montecchi, 2007,Thomas and Guven, 1994). For quality control purposes, the intercept factor of parabolic trough systems can be measured and necessary improvements made (Pottler et al., 2014). Moreover, with improvements in the manufacture of these systems, most of the mentioned errors can be minimised. Wendelin (2006) presented optical characterization results of parabolic trough systems using a video scanning Hartmann optical tester (VSHOT) for different system configurations. Using space frames from different suppliers, the average root mean square (rms) slope errors obtained in their study ranged from as high as $4.46 \mathrm{mrad}$ to about 3.0 mrad. Other studies that have considered investigations of optical performance in the analysis of parabolic trough systems include (Skouri et al., 2013, Balghouthi et al., 2014, Xu et al., 2014). In these studies, the presence of optical errors is evident. For example Balghouthi et al. (2014) considered slope errors in the range $-3 \mathrm{mrad}$ to $+27 \mathrm{mrad}$ while in $\mathrm{Xu}$ et al. (2014) longitudinal optical errors (optical errors at the optical surface in the longitudinal, y-direction) of 6 mrad were obtained for the optimised system. Transverse optical errors (optical errors at the optical surface in the transverse, $x$-direction) for the optimised system were also $6 \mathrm{mrad}$ (Xu et al, 2014).

Regarding receiver thermal performance, several studies are available in literature on the thermal performance of parabolic trough receivers (Lüpfert et al., 2008,Burkholder and Kutscher, 2009, Burkholder and Kutscher, 2008, Ouagued et al., 2013, Li and Wang, 2006, Mokheimer et al., 2014, Y1lmaz and Söylemez, 2014, Marif et al., 2014). Determination of heat flux distribution on the receiver is crucial to the analysis of the thermal performance of the system. With the realistic heat flux distribution on the receiver, receiver peak temperatures, circumferential temperature 
gradients, receiver thermal loss can be precisely determined. As such, several studies have been carried out to determine the heat flux distribution on the receiver tube. Jeter (1986) calculated the flux distribution in parabolic trough collectors using a semi-finite formulation. In another study, Jeter (1987) showed analytically the computation of the intercept factor and optical efficiency of parabolic trough concentrators. Other authors have used Monte Carlo ray tracing to determine heat flux distribution on a receiver tube of a parabolic trough system and subsequently analysed the thermal performance of the system (He et al., 2011, Cheng et al., 2012, Mwesigye et al., 2014b, Xiao et al., 2014). In these studies and some other studies available in literature, the detailed influence of optical errors on the thermal and thermodynamic performance of the parabolic trough system is not presented. In most cases, it is assumed that optical errors are negligible, which is not necessarily the case as was shown in the measurements of slope errors by Wendelin (2006). Therefore, the focus of this study is to numerically investigate the optical, thermal and thermodynamic performance of a parabolic trough collector at different values of slope and specularity errors. The Monte Carlo Ray Trace method provides a convenient and flexible way of changing the optical and geometrical properties of the collector, it has become an important tool for the analysis of concentrating solar systems (He et al., 2011, Cheng et al., 2012, Le Roux et al., 2014). This study focuses on the optical analysis and determination of the actual heat flux distribution on the receiver's absorber tube using an optical modelling software based on the Monte Carlo Ray tracing, SolTrace (SolTrace, 2012) and the coupling of the obtained heat flux profiles with a computational fluid dynamics tool, to investigate the thermal performance. Moreover, using the second law of thermodynamics, the thermodynamic performance of the parabolic trough receiver is investigated and discussed. 


\section{Physical model}

To perform an optical analysis on the parabolic trough collector system, accurate specification of the geometry of the system is crucial. Figure 1(a) shows the 3-D model of a parabolic trough collector system under consideration. Actual parabolic trough systems are made up of different panels joined together. It is assumed that the effect of the gap between the different panels does not have a significant effect on the performance of the system. As such, a simplified collector with a continuous parabolic surface was used as shown. Figure 1(b) shows the cross-section view of the parabolic trough receiver. Figure 2 shows the cross-section view of the parabolic trough collector together with the receiver and a trace of some of the incident rays. The geometry of the collector is defined by the equation of a parabola as

$x^{2}=4 f y$

The focal length is related to the rim angle and aperture width as

$$
f=a / 4 \tan \left(\varphi_{r} / 2\right)
$$

Where $a$ is the aperture width, $f$ is the focal length and $\varphi_{r}$ is the rim angle. From Eqs. (2) and (3), the geometry of the collector is fully defined given any two parameters. The concentration ratio $\left(C_{R}\right)$ used in this study is the geometrical concentration ratio, it relates the projected area of the collector to the projected area of the absorber tube as

$$
C_{R}=\frac{A_{a}}{A_{r}}=\frac{a \times L}{d_{r i} \times L}
$$

Detailed description of the parabolic trough collector geometry is given in (Duffie and Beckman, 2006). The computational domain of the receiver tube used in the analysis of the thermal and thermodynamic performance of the receiver is shown in Fig. 3. For the assumed normal 
incidence condition, the incident heat flux will be symmetrical, thus, only half of the receiver was considered as shown.

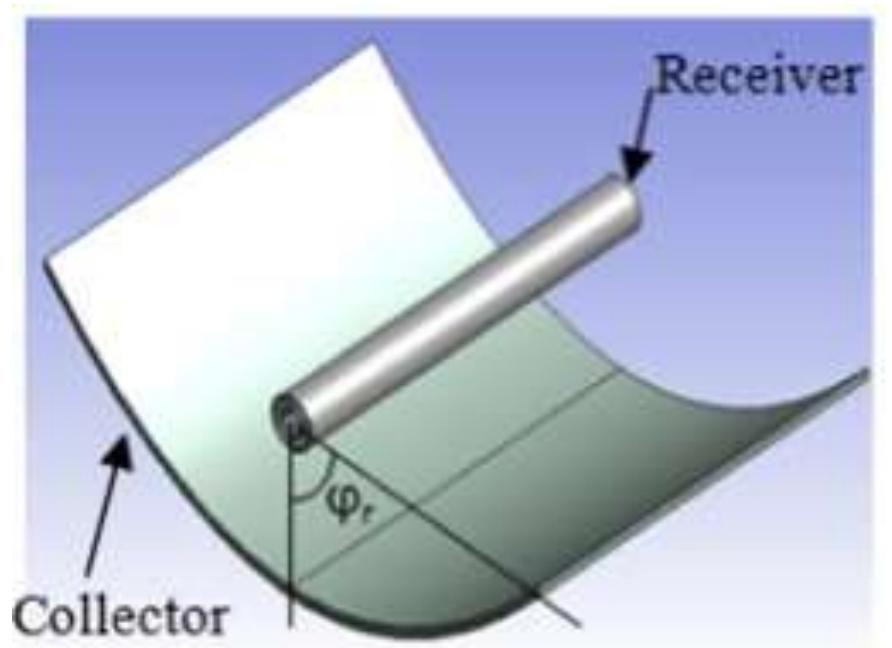

(a)

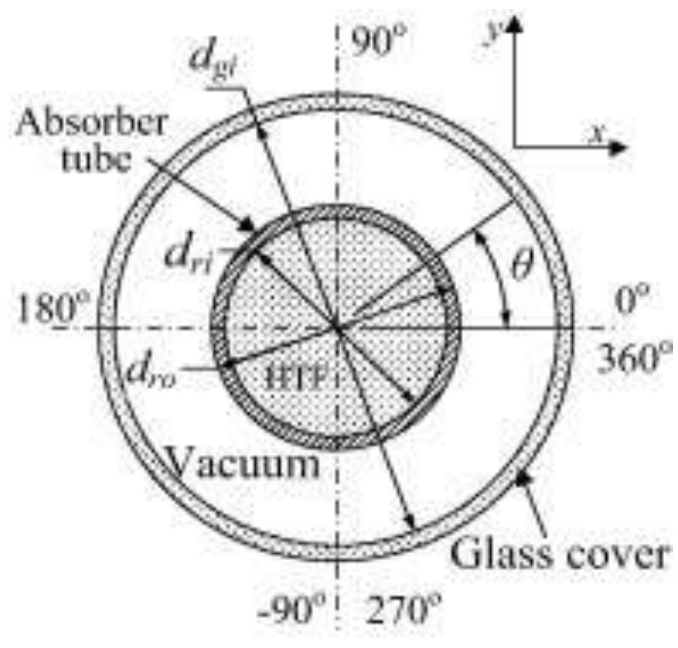

(b)

Fig. 1. Physical models of parabolic trough system and receiver: (a) 3-D model of the parabolic trough system and (b) cross-section view of the parabolic trough receiver.

\section{Receiver}

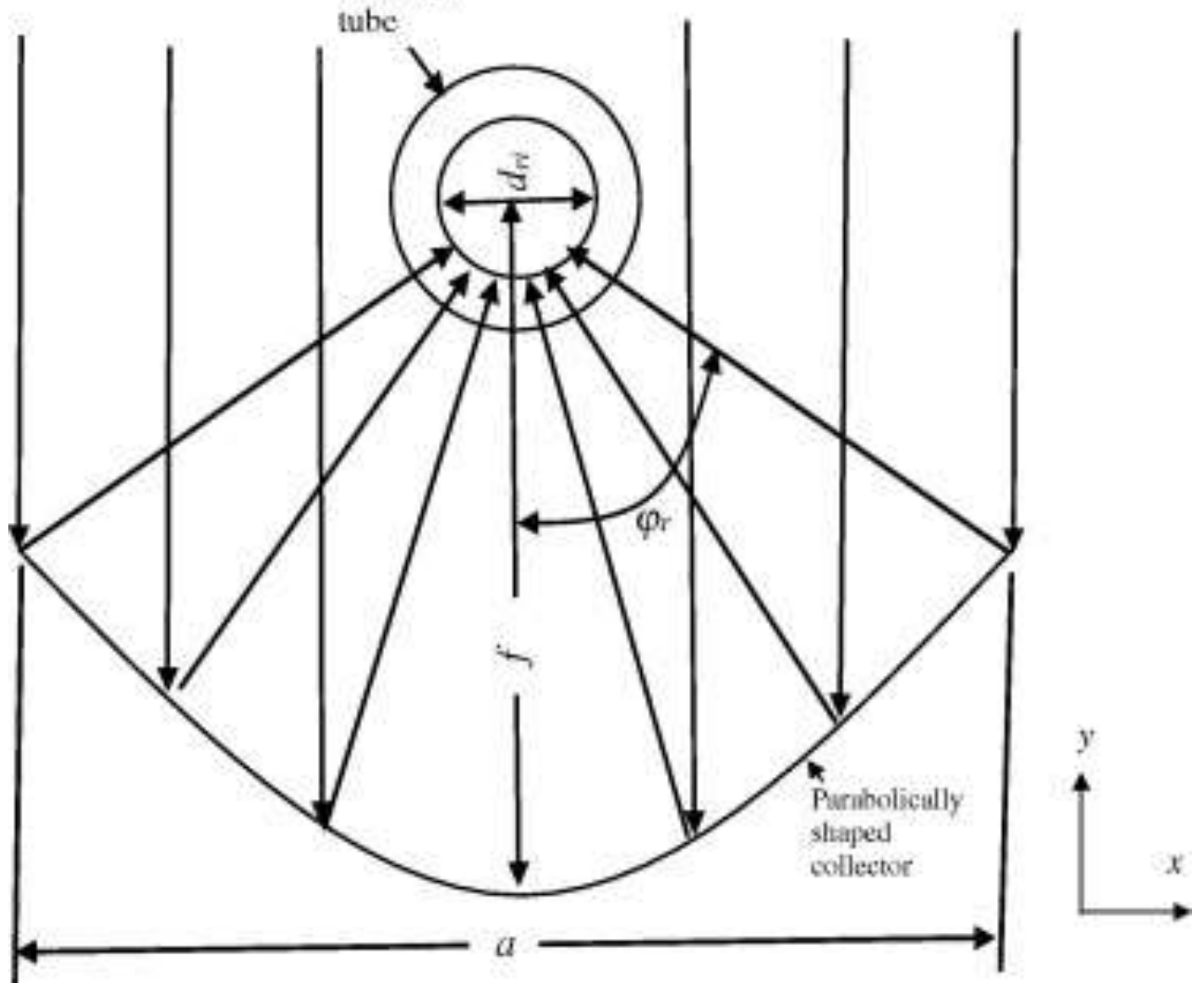

Fig. 2. Cross-section view of the parabolic trough collector system with a trace of some incident rays. 


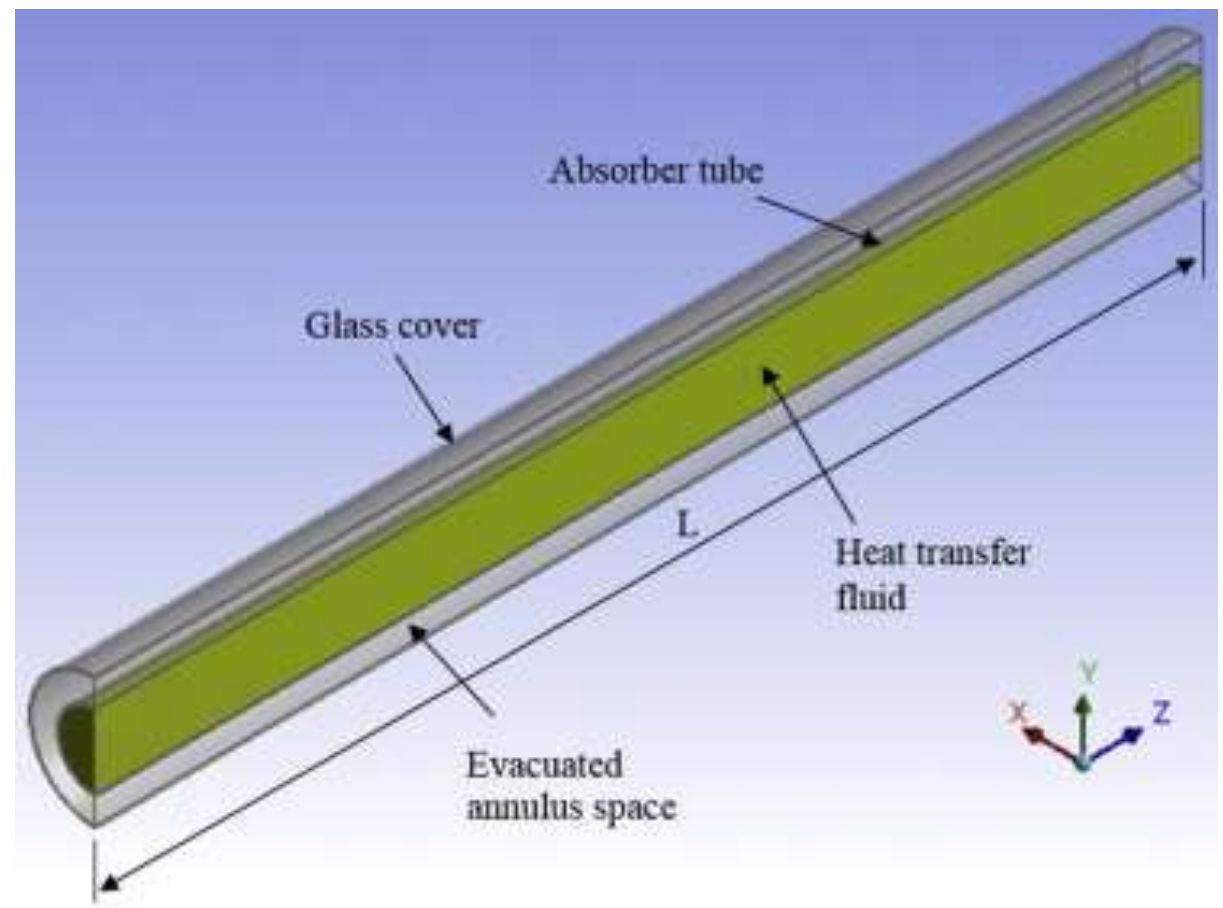

Fig. 3. 3-D symmetrical computational domain of the parabolic trough receiver used.

\section{Optical and thermal analysis}

To accurately define the optical performance of parabolic trough collectors, the determination of geometrical errors and the influence of these errors on system performance is essential. The most commonly used, straight forward and accurate method is statistical ray tracing (Bendt et al., 1979). With this method, normal distribution functions of angular deviations from perfect optics are used to describe all kinds of errors (Pottler et al., 2014). The optical errors are represented as normal probability distributions. The total error is given as the sum of individual errors occurring in the system (Güven and Bannerot, 1986) as

$$
\sigma_{\text {tot }}^{2}=\sigma_{\text {sun }}^{2}+(2 \sigma)_{\text {slope }}^{2}+\sigma_{\text {track }}^{2}+\sigma_{\text {mirror }}^{2}
$$

Where $\sigma_{\text {sun }}$ represents the standard deviation of the sun's energy distribution, $\sigma_{\text {slope }}$ is the slope error distribution, $\sigma_{\text {track }}$ is the tracking error distribution and $\sigma_{\text {mirror }}$ is the specularity error distribution. These errors are random in nature and are accurately represented by normal or 
Gaussian distributions (Güven and Bannerot, 1986). Compared to other errors, twice the standard deviation of the slope error is employed since reflector optics result in doubling of the slope error as the deviation from the mean specular direction (Güven and Bannerot, 1986).

Non-random errors are deterministic in nature and can degrade the collector performance significantly. They are mainly gross errors in manufacture, assembly and operation of the collector. They include reflector profile errors, consistent misalignment of the collector with the sun, and misalignment of the receiver with the effective focus of the sun. In this study, it is assumed that quality control measures are in place to reduce the non-random errors significantly and therefore, their impact on the optical performance of the system is minimal. Furthermore, tracking errors are assumed small compared to the slope and mirror errors. Moreover, for normal incidence, the tracking error can be assumed negligible (Balghouthi et al., 2014). Gee et al., (2010) showed that by using the Gaussian sun distribution results from ray tracing and those from the Gaussian approximation differ by less than 3\% for slope errors up to $5 \mathrm{mrad}$. As such, sun errors were taken into consideration by specifying the sun shape as a Gaussian distribution with $\sigma_{\text {sun }}=2.6 \mathrm{mrad}$ similar to the study by Balghouthi et al., (2014). This error term remained fixed throughout the study. As such, only the influence of slope errors and mirror errors on the optical, thermal and thermodynamic performance of the receiver is presented in this study.

For thermal analysis of the receiver, determination of receiver thermal loss as well as the thermal efficiency of the system is essential. Among other factors, the receiver thermal loss depends on the vacuum quality in the receiver's annulus space, geometry of the glass envelope and receiver ends, absorber tube temperatures, properties of the glass and thermal emittance of the absorber tube coating (Lei et al., 2013). Moreover, receivers with evacuated glass envelopes have a lower thermal loss compared to receivers with non-evacuated envelopes (Dudley et al., 1994). This is 
because evacuating the receiver annulus space suppresses the natural convection heat loss. Similar to conventional receivers, the receiver's annulus space was considered evacuated to very low pressures (about $0.013 \mathrm{~Pa}$ ) (Price et al., 2002), such that natural convection heat loss between the receiver's absorber tube and the receiver's glass cover is suppressed. Additionally, the receiver's absorber tube has an outer wall that is coated with a cermet selective coating giving it low emissivity for infrared radiation and high absorptivity for the incoming solar radiation. Under steady-state conditions and for a receiver with a non-evacuated glass envelope, the receiver thermal loss can be obtained as detailed in (Duffie and Beckman, 2006) as

$$
Q_{\text {loss }}=\frac{2 \pi k_{e f f, a i r} L}{\ln \frac{d_{g i}}{d_{r o}}}\left(T_{r o}-T_{g i}\right)+\frac{\pi d_{r o} L \vartheta\left(T_{r o}{ }^{4}-T_{g i}{ }^{4}\right)}{\frac{1}{\varepsilon_{r o}}+\frac{1-\varepsilon_{g i}}{\varepsilon_{g i}}\left(\frac{d_{r o}}{d_{g i}}\right)}
$$

Equation (6) gives the thermal loss from the absorber tube to the glass cover. In Eq. (6), $k_{\text {eff,air }}$ is the effective thermal conductivity of air, which depends on the pressure in the annulus space (vacuum quality) and also the temperature of the air in the annulus space. For very low vacuum pressures as considered in this study, $k_{\text {eff,air }}$ approaches zero and only the radiation heat loss, second term in Eq. (6) is considered (Duffie and Beckman, 2006, Lei et al., 2013). An energy balance easily shows that the thermal loss in Eq. (6) is equivalent to the heat loss through the glass cover by conduction and heat loss from the glass cover to the surroundings by both radiation and convection. The detailed equations for thermal analysis of parabolic trough receivers can be found in (Duffie and Beckman, 2006, Lei et al., 2013, Marif et al., 2014).

The emissivity of the glass is taken to be constant and is given as $\varepsilon_{g i}=0.86$ (Forristall, 2003). The absorber tube emissivity is temperature dependent. For an absorber tube with a cermet selective coating, the emissivity $\left(\varepsilon_{r o}\right)$ was taken as given by (Dudley et al., 1994) as 
$\varepsilon_{r o}=0.000327\left(T_{r o}+273.15\right)-0.065971$

In which $T_{r o}$ is the absorber tube temperature in ${ }^{\circ} \mathrm{C}$. The emissivity value given Eq. (7) was used only in the comparison of the present study results with experimental results of (Dudley et al., 1994). For the rest of the work, the emissivity of the PTR70 receiver was used. The emissivity of the PTR70 receiver is given by (Burkholder and Kutscher, 2009) as

$\varepsilon_{r o}=0.062+2 \times 10^{-7} T_{r o}^{2}$

In Eq. (8), the absorber tube temperature $T_{r o}$ is in ${ }^{\circ} \mathrm{C}$. The emissivity values given by Eq. (8) correspond to the values of emissivity of tubular metal sample with coating type 1 in a recent study by (Bartelmeß et al., 2014).

The overall thermal efficiency, which is the ratio of the useful energy delivered to the user and the solar radiation incident on the collector is given by

$$
\eta_{t h, o}=\frac{q_{u}}{I_{b} A_{a}}
$$

The thermal efficiency based on the solar radiation absorbed by the receiver tube is given by

$$
\eta_{t h, a}=\frac{q_{u}}{\eta_{o} I_{b} A_{a}}
$$

The useful energy delivered, $q_{u}$ is given by

$$
q_{u}=\dot{m} c_{p}\left(T_{\text {outlet }}-T_{\text {inlet }}\right)
$$




\section{Numerical analysis}

In this study, a combined Monte Carlo ray tracing and computational fluid dynamics approach was used. The sections below give the details of the numerical modelling.

\subsection{Governing equations}

The governing equations for turbulent flow in the receiver's absorber tube are the Reynolds averaged equations for the conservation of mass, momentum and energy given by (ANSYS, 2014b):

Continuity

$$
\frac{\partial\left(\rho \bar{u}_{i}\right)}{\partial x_{i}}=0
$$

Momentum equation

$$
\frac{\partial}{\partial x_{j}}\left(\rho \bar{u}_{i} \bar{u}_{j}\right)=-\frac{\partial \bar{P}}{\partial x_{i}}+\frac{\partial}{\partial x_{j}}\left[\mu\left(\frac{\partial \bar{u}_{i}}{\partial x_{j}}+\frac{\partial \bar{u}_{j}}{\partial x_{i}}\right)-\frac{2}{3} \mu \frac{\partial \bar{u}_{i}}{\partial x_{i}} \delta_{i j}-\rho \overline{u_{i}^{\prime} u_{j}^{\prime}}\right]
$$

Energy equation

$$
\frac{\partial}{\partial x_{j}}\left(\rho \bar{u}_{j} C_{p} \bar{T}\right)=\frac{\partial}{\partial x_{j}}\left(\lambda \frac{\partial \bar{T}}{\partial x_{j}}+\frac{\mu_{t}}{\sigma_{h, t}} \frac{\partial\left(C_{P} \bar{T}\right)}{\partial x_{j}}\right)+\bar{u}_{j} \frac{\partial \bar{P}}{\partial x_{j}}+\left[\mu\left(\frac{\partial \bar{u}_{i}}{\partial x_{j}}+\frac{\partial \bar{u}_{j}}{\partial x_{i}}\right)-\frac{2}{3} \mu \frac{\partial \bar{u}_{i}}{\partial x_{i}} \delta_{i j}-\rho \overline{u_{i}^{\prime} u_{j}^{\prime}}\right] \frac{\partial \bar{u}_{i}}{\partial x_{j}}
$$

The averaging process leading to Eqs. (11) to (13) presents a closure problem requiring additional equations for the solution of these equations to be obtained. Several turbulence models to solve this closure problem have been derived and presented. Of these models, the eddy viscosity models provide a means of representing the Reynolds stresses with low computation 
cost. With this, the Reynolds stresses in Eqs. (12) and (13) are related to strain according to (ANSYS, 2014b)

$$
-\rho \overline{u_{i}^{\prime} u_{j}^{\prime}}=\mu_{t}\left(\frac{\partial \bar{u}_{i}}{\partial x_{j}}+\frac{\partial \bar{u}_{j}}{\partial x_{i}}\right)-\frac{2}{3}\left(\rho k+\mu_{t} \frac{\partial \bar{u}_{k}}{\partial x_{k}}\right) \delta_{i j}
$$

where $k$ is the turbulent kinetic energy given by (ANSYS, 2014b)

$$
k=\frac{1}{2}\left(\overline{u^{\prime 2}}+\overline{v^{\prime 2}}+\overline{w^{\prime 2}}\right)
$$

In the present study, the realisable $k-\varepsilon$ model (Shih et al., 1995), an improvement of the widely used standard $k-\varepsilon$ models, was used. The model requires two additional equations for the turbulent kinetic energy $(k)$ and turbulent dissipation rate $(\varepsilon)$. The turbulent kinetic energy is given by (ANSYS, 2014b, Shih et al., 1995)

$$
\frac{\partial}{\partial x_{j}}\left(\rho k \bar{u}_{j}\right)=\frac{\partial}{\partial x_{j}}\left[\left(\mu+\frac{\mu}{\sigma_{k}}\right) \frac{\partial k}{\partial x_{j}}\right]+G_{k}-\rho \varepsilon
$$

and the turbulent dissipation rate $(\varepsilon)$ is given by ( ANSYS, 2014b,Shih et al., 1995)

$$
\frac{\partial}{\partial x_{j}}\left(\rho \varepsilon \bar{u}_{j}\right)=\frac{\partial}{\partial x_{j}}\left[\left(\mu+\frac{\mu_{t}}{\sigma_{\varepsilon}}\right) \frac{\partial \varepsilon}{\partial x_{j}}\right]+\rho C_{1} S \varepsilon-\rho C_{2} \frac{\varepsilon^{2}}{k+\sqrt{v \varepsilon}}
$$

In Eq. (16), $G_{k}$ is the production of turbulent kinetic energy given by

$$
G_{k}=-\rho \overline{u_{i}^{\prime} u_{j}^{\prime}} \frac{\partial \bar{u}_{j}}{\partial x_{i}}
$$

From Eq. (18), the production of turbulent kinetic energy $\left(G_{k}\right)$ can be obtained as

$$
G_{k}=\mu_{t} S^{2}
$$


The eddy viscosity is given by (ANSYS, 2014b)

$$
\mu_{t}=\rho C_{\mu} \frac{k^{2}}{\varepsilon}
$$

Detailed determination of the realisable $k-\varepsilon$ model constants and modelling procedure is given in ANSYS FLUENT® theory guide (ANSYS, 2014b). The model constants for the realisable $k-\varepsilon$ model are:

$$
C_{1}=\max \left[0.43, \frac{\eta}{\eta+5}\right], \eta=S \frac{k}{\varepsilon}, S \equiv \sqrt{2 S_{i j} S_{i j}}, C_{2}=1.9, \sigma_{k}=1, \sigma_{\varepsilon}=1.2 \text { and } S_{i j}
$$

$S_{i j}$ represents the rate of linear deformation of a fluid element. In total, there are nine components in three dimensions. Three of these components are linear elongation deformation components and six are shearing and deformation components (ANSYS, 2014b).

\subsection{Ray tracing}

To investigate the effect of slope errors and specularity errors on heat flux distribution and the intercept factor, Monte Carlo ray tracing was used. The Monte Carlo ray tracing methodology was implemented in an optical modelling tool, SolTrace (SolTrace, 2012). This involves specification of the sun shape, taken as a Gaussian distribution with $\sigma_{\text {sun }}=2.6$ mrad in this study, followed by geometry of the parabolic trough system, which was obtained by using Eq. (2) and (3). After which the optical properties of each of the components of the parabolic trough system were specified in conjunction with the corresponding optical errors. A maximum number of rays from the sun was subsequently specified and traced as it went through several interactions with 
the different components of the parabolic trough system. The maximum number of sun generated rays was set to $10^{8}$ and $10^{6}$ was specified as the number of desired ray interactions. These values were sufficiently large to give an accurate heat flux profile as confirmed in the validation of our ray trace results. The values of optical properties of the absorber tube, the receiver glass cover and the collector mirror used are given in Table 1. For the receiver's glass cover, the reflectivity was taken as zero, the transmissivity was taken as 0.97 and no optical errors were considered. For the absorber tube, the transmissivity was taken as zero, the reflectivity was taken as 0.04 to give the required absorptivity of 0.96 and no optical errors were considered. For the collector

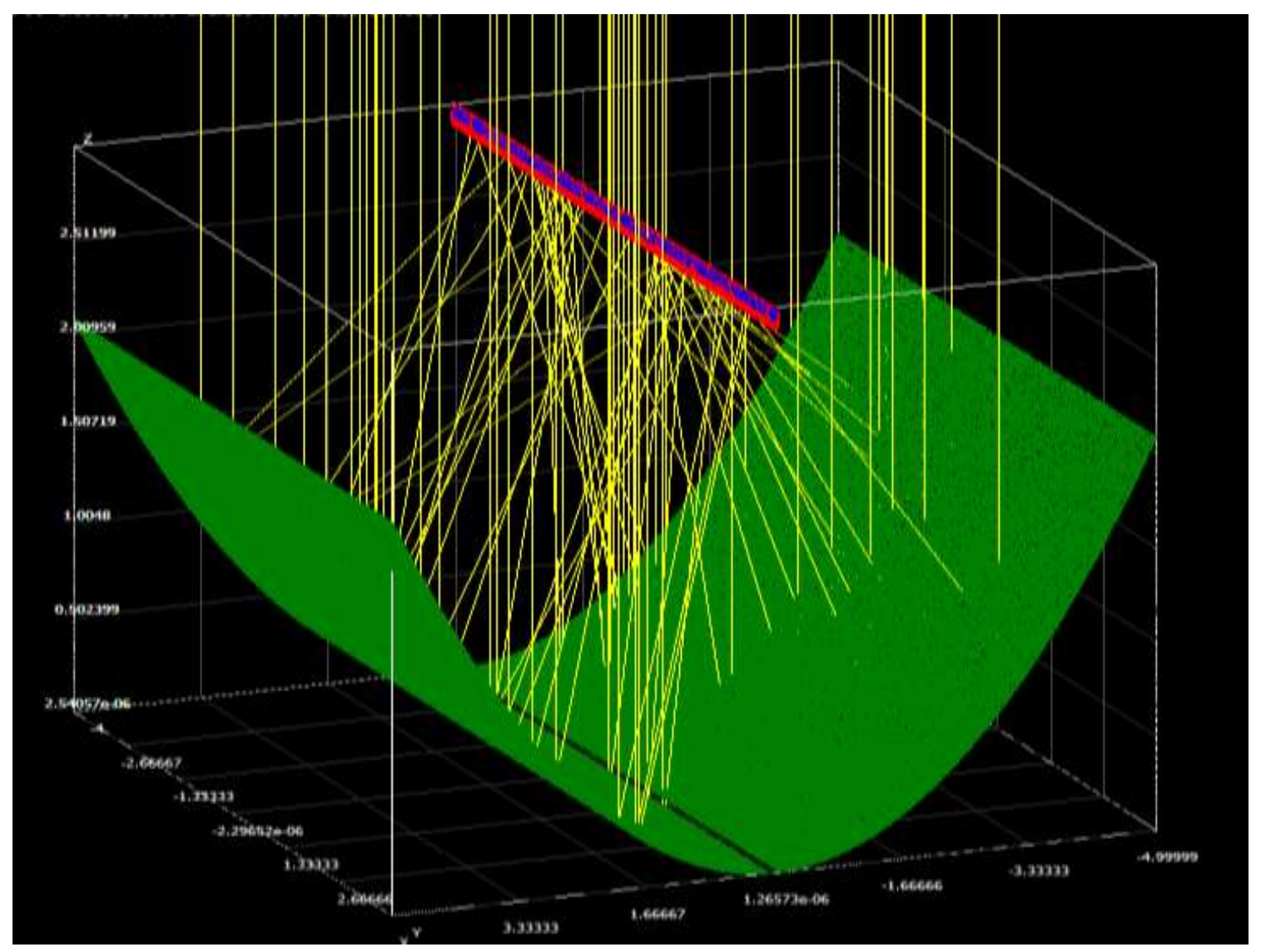

Fig. 4 Sample trace of incident rays for a parabolic trough system with an aperture width of $10 \mathrm{~m}$ and a rim angle, $\varphi_{r}$ $=80^{\circ}$ 
mirror, a reflectivity value of 0.96 was used, the transmissivity was taken as zero and the slope and mirror errors were varied as required in the ranges provided in Table 1 . The sample interaction of incident rays among the different components in the parabolic trough system is shown in Fig. 4. From this, the distribution of heat flux on the receiver's absorber tube and the intercept factor were obtained.

\subsection{Boundary conditions}

The boundary conditions used in this study were: (1) Non-uniform heat flux on the absorber tube's outer wall which was determined by using Monte Carlo ray tracing in SolTrace (SolTrace, 2012). A direct normal irradiance (DNI) of $1000 \mathrm{~W} / \mathrm{m}^{2}$ was assumed throughout this work. At

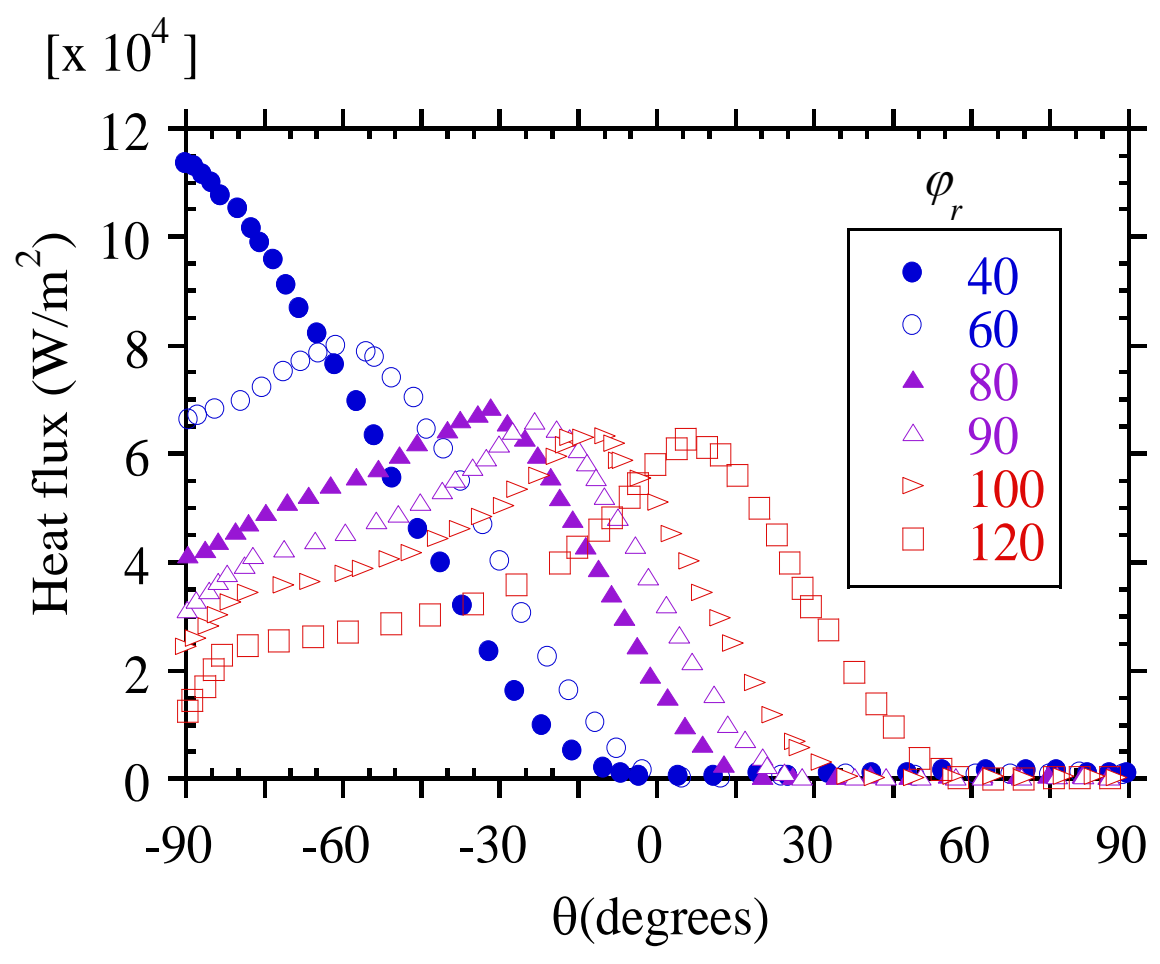

Fig. 5 Heat flux distribution as a function of absorber tube circumferential angle and collector rim angle at a concentration ratio of 86 
different rim angles, a sample heat flux profile on half of the receiver $\left(-90^{\circ} \leq \theta \leq 90^{\circ}\right)$ is shown in Fig. 5. (2) A uniform velocity distribution and pressure outlet boundary conditions were used for the absorber tube's inlet and outlet, respectively. For the length of the receiver and the diameter of the absorber tube considered, entrance effects did not influence the results significantly according to the preliminary analysis we did. This is likely because for turbulent flow, the entrance length is approximately $10 \mathrm{D} \approx 10 * 0.066 \approx 0.66 \mathrm{~m}$ compared to $5 \mathrm{~m}$ used in this study. (3) No-slip and no-penetration boundary condition was specified for all the receiver walls. (4) The receiver's annulus space is evacuated and only radiation heat transfer takes place, therefore, a symmetry boundary condition was used for the inlet and outlet of the receiver's annulus space to ensure that the normal gradients of all flow variables are zero. (5) On the outer wall of the glass cover, a mixed boundary condition is used to account for both radiation and convection heat transfer. Stefan Boltzmann's law gives radiation between the glass cover and the sky. The sky is taken as a large enclosure, the parabolic mirror is not considered in the computation of radiative heat transfer. Convection heat transfer from the receiver's glass was modelled by specifying a convection heat transfer coefficient and free stream temperature. The sky temperature is given by (Swinbank, 1963) as

$$
T_{\text {sky }}=0.0552 T_{a m b}^{1.5}
$$

The wind heat transfer coefficient is given by (Mullick and Nanda, 1989) as

$$
h_{w}=V_{w}^{0.58} d_{g o}{ }^{-0.42}
$$

The ambient temperature $\left(T_{a m b}\right)$ was kept at $300 \mathrm{~K}$ and the wind speed $\left(V_{w}\right)$ was fixed at $2 \mathrm{~m} / \mathrm{s}$ perpendicular to the axis of the receiver. The parabolic trough system considered in this study has a rim angle of $80^{\circ}$ and a concentration ratio of 86 . Table 1 shows the summary of the other 
parameters used in this study. A receiver with dimensions similar to commercially available receivers was used in this study (Dudley et al., 1994, Schott, 2014).

Table 1 Geometrical and optical values of the parabolic trough collector used in this study

\begin{tabular}{cccc}
\hline Parameter & Value & Parameter & Value \\
\hline$a$ & $6 \mathrm{~m}$ & $d_{r i}$ & $0.066 \mathrm{~m}$ \\
$L$ & $5 \mathrm{~m}$ & $d_{r o}$ & $0.070 \mathrm{~m}$ \\
$\rho_{m}$ & 0.96 & $\tau_{g}$ & 0.97 \\
$\varphi_{r}$ & $80^{\circ}$ & $\alpha_{a b s}$ & 0.96 \\
$C_{R}=A_{d} / A_{r}$ & 86 & $\sigma_{\text {slope }}$ & $0-5 \mathrm{mrad}$ \\
$\varepsilon_{g i}$ & 0.86 & $\sigma_{\text {mirror }}$ & $0-4 \mathrm{mrad}$ \\
$d_{g i}$ & $0.115 \mathrm{~m}$ & $d_{g o}$ & $0.125 \mathrm{~m}$ \\
\hline
\end{tabular}

\subsection{Entropy generation analysis}

To assess the thermodynamic performance of the receiver at different conditions, the entropy generation analysis is a good tool. The entropy generation minimisation method is widely used to design and optimise thermal systems, as well as components of these systems. For this study, the entropy generation rates of interest are the ones due to heat transfer and fluid friction irreversibilities. These entropy generation rates were obtained locally from temperature and velocity fields obtained from the numerical analysis. The entropy generation rates were determined according to the general equations presented by (Kock and Herwig, 2004, Kock and Herwig, 2005).

The entropy generation due to the fluid friction irreversibility is given by (Kock and Herwig, 2005)

$S_{g e n, F}^{\prime \prime \prime}=\frac{\mu}{\bar{T}}\left(\frac{\partial \bar{u}_{i}}{\partial x_{j}}+\frac{\partial \bar{u}_{j}}{\partial x_{i}}\right) \frac{\partial \bar{u}_{i}}{\partial x_{j}}+\frac{\rho \varepsilon}{\bar{T}}$ 
In Eq. (24), the first term is the entropy production by direct dissipation and the last term is the entropy production by indirect (turbulent) dissipation.

The entropy generation due to the heat transfer irreversibility is given by (Kock and Herwig, 2005)

$$
S_{g e n, H}^{\prime \prime \prime}=\frac{\lambda}{\bar{T}^{2}}(\nabla \bar{T})^{2}+\frac{\alpha_{t}}{\alpha} \frac{\lambda}{\bar{T}^{2}}(\nabla \bar{T})^{2}
$$

The first term in Eq. (25) represents the entropy production by heat transfer with mean temperatures and the second term represents entropy production with fluctuating temperatures. The symbol $\lambda$ is the fluid thermal conductivity, symbols $\alpha$ and $\alpha_{t}$ are the thermal diffusivities.

From the local entropy generation rates in Eqs. (24) and (25), the total entropy generation rate for a fluid occupying a volume $V$ is obtained from

$$
S_{g e n}=\iiint_{V} S_{g e n}^{\prime \prime \prime} d V
$$

where $S_{g e n}^{\prime \prime \prime}=S_{g e n, F}^{\prime \prime \prime}+S_{g e n, H}^{\prime \prime \prime}$

\subsection{Thermophysical properties}

Syltherm800 is the heat transfer fluid used in this study. Syltherm800 was selected since it is commonly used in test facilities of parabolic trough systems such as the Aztrack test facility at Sandia National Laboratory (Dudley et al., 1994) and the linear focusing test facilities at Plataforma Solar de Almeria (PSA, 2016). It is worth mentioning that the type of heat transfer fluid used does not significantly affect the performance of a parabolic trough system as was shown by Forristall (2003). The properties of Syltherm800 are temperature dependent. For this study, curve-fitted polynomials obtained using regression analysis from manufacturer data sheets 
were used (Dow, 2012). The specific heat capacity $\left(C_{p}\right)$, the density $(\rho)$ and the thermal conductivity $(\lambda)$ are given by the polynomials given by Eqs. (27) to (29) respectively.

For $233.15 \leq T \leq 673 \mathrm{~K}$

$$
\begin{aligned}
& C_{p}=1.10787+1.70736 \times 10^{-3} T(\mathrm{~kJ} / \mathrm{kg} \mathrm{K}) \\
& \rho=1.2691 \times 10^{3}-1.52115 T+1.79133 \times 10^{-3} T^{2}-1.67145 \times 10^{-6} T^{3}\left(\mathrm{~kg} / \mathrm{m}^{3}\right) \\
& \lambda=1.90134 \times 10^{-1}-1.88053 \times 10^{-4} T(\mathrm{~W} / \mathrm{m} \mathrm{K})
\end{aligned}
$$

The viscosity is given by piecewise polynomials given by Eqs.(30) and (31).

For $233.15 \leq T \leq 343 \mathrm{~K}$ :

$$
\begin{aligned}
\mu= & 5.14887 \times 10^{4}-9.61656 \times 10^{2} T+7.50207 T^{2}-3.12468 \times 10^{-2} T^{3}+7.32194 \times 10^{-5} T^{4} \\
& -9.14636 \times 10^{-8} T^{5}+4.75624 \times 10^{-11} T^{6}(\mathrm{mPa} \mathrm{s})
\end{aligned}
$$

For $343 \leq T \leq 673.15 \mathrm{~K}$

$$
\begin{aligned}
\mu= & 9.88562 \times 10^{1}-7.30924 \times 10^{-1} T+2.21917 \times 10^{-3} T^{2}-3.42377 \times 10^{-6} T^{3} \\
& +2.66836 \times 10^{-9} T^{4}-8.37194 \times 10^{-13} T^{5}(\mathrm{mPa} \mathrm{s})
\end{aligned}
$$

\subsection{Computation procedure}

The numerical computational procedure involved solid modelling of the receiver in ANSYS design modeller, discretisation of the receiver in ANSYS meshing and solving the governing equations alongside the boundary conditions using the finite volume method implemented in a commercial computational fluid dynamics code, ANSYS Fluent (ANSYS, 2014a). The computational domain was discretised using mainly hexahedral elements with a structured mesh in the wall-normal directions as shown in Fig. 6. A total of 725,460 - 825,652 mesh elements were sufficient to give a mesh independent solution as well as a good quality mesh. More mesh 


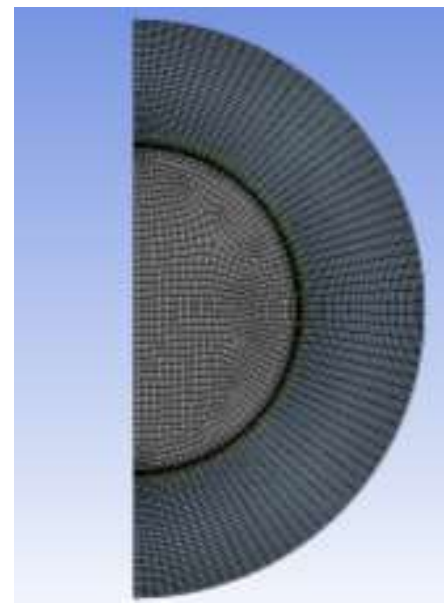

(a)

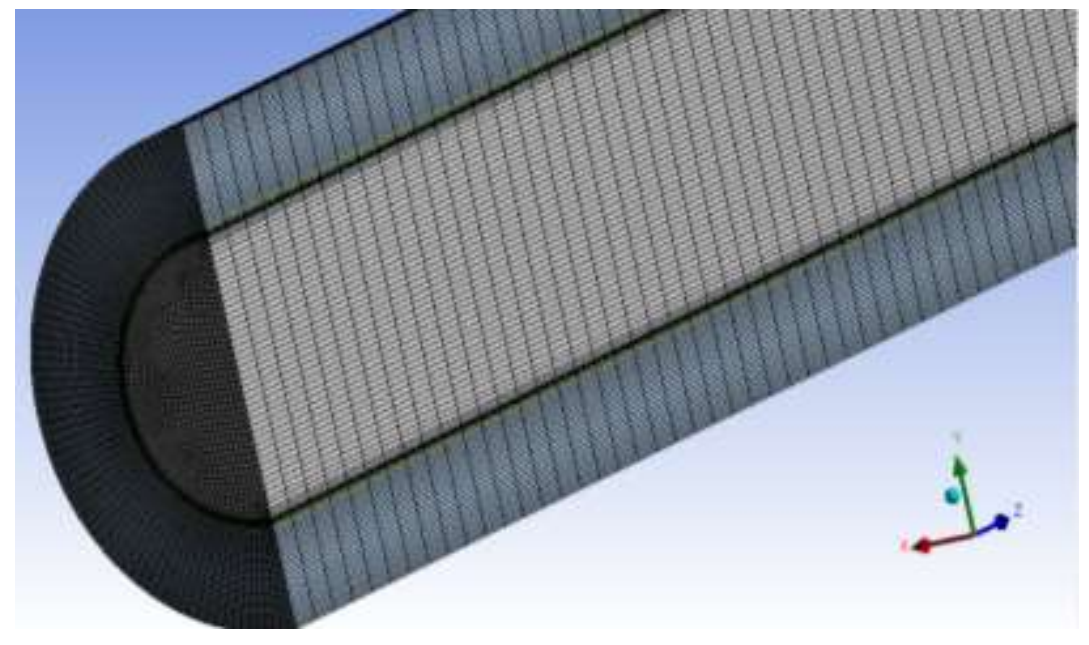

(b)

Fig. 6 Representative discretised domain (grid) of the parabolic trough receiver used in this study: (a) cross-section view and (b) lateral view

elements were used at high Reynolds numbers since significantly smaller prism layers were required to capture the near wall regions. Second-order upwind schemes were employed for integrating the governing equations together with the boundary conditions over the computational domain. The SIMPLE algorithm was used for coupling pressure and velocity. Radiation heat transfer in the annulus was modelled using the Discrete Ordinates model (ANSYS, 2014b), with air as a non-participating medium. In order to capture the near-wall gradients, the dimensionless wall coordinate $y^{+}$of less than 1 was ensured in all simulations. The dimensionless wall coordinate, $y^{+}$is estimated from $y^{+}=y \mu_{\tau} / v$, where $v$ is the fluid's kinematic viscosity, $y$ is the distance from the wall, and $u_{\tau}$ is the friction velocity. To predict the near wall cell size, the distance $y$ was calculated as $y=y^{+} \mu / \mu_{\tau} \rho$. The realisable $k$ - $\varepsilon$ model (ANSYS, 2014a) was used for turbulence modelling. The realisable $k-\varepsilon$ is an improvement over the standard $k-\varepsilon$ model (ANSYS, 2014b). In a previous investigation, it was shown to approach the more accurate but computationally expensive Reynolds stress model (Mwesigye et al., 2016). The enhanced 
wall-treatment option was used for modelling the near-wall regions. For accurate prediction of entropy generation rates, the solution was run until the scaled residuals of all quantities ceased changing for more than 100 successive iterations. This convergence was obtained with scaled residuals of mass, momentum, turbulent kinetic energy $(k)$ and turbulence dissipation rate $(\varepsilon)$ less than $10^{-5}$ while the energy residuals were less than $10^{-8}$.

\section{Results and discussions}

\subsection{Validation of numerical models}

Our numerical results have been validated with data available in literature. The validation of the ray tracing results is shown in Fig. 7. As shown, the same trend exists when compared to the results of Jeter (1986), He et al. (2011) and Yang et al. (2010). Moreover, good agreement was

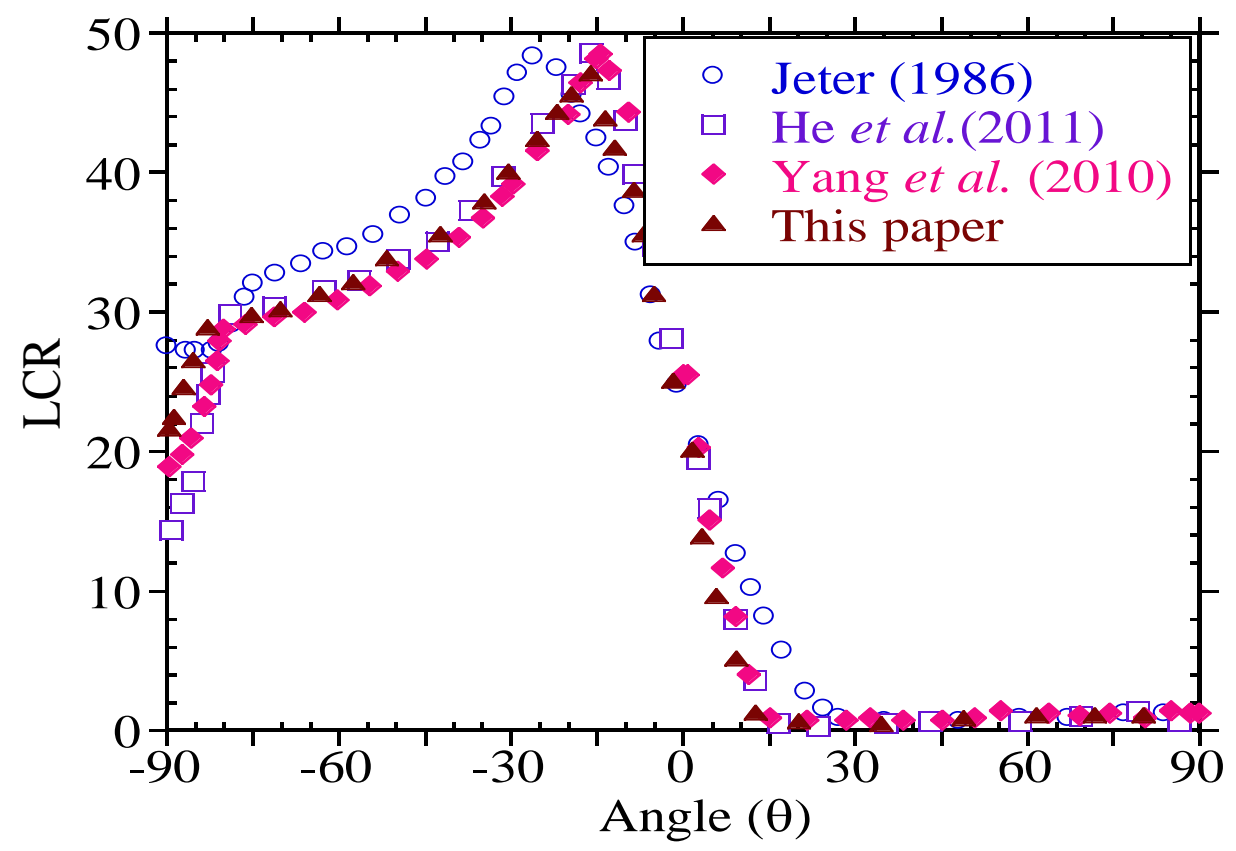

Fig. 7 Comparison of present study local concentration ratio as a function of absorber tube circumferential angle ( $\theta$ ) with literature 
obtained for the entire range of receiver circumferential angles as shown. In Fig. 7, LCR is the local concentration ratio, defined as the ratio of the actual heat flux on the absorber tube to the incident solar radiation. All the studies presented in Fig. 7 assume a collector mirror of perfect shape and specularly reflecting, therefore, negligible slope errors and specularity errors.

The validation of the thermal performance of the receiver model was done using data from Sandia national laboratories using similar parameters as was used in the experiment (Dudley et al., 1994). Good agreement was achieved for heat transfer fluid temperature gain $(\Delta T)$ and collector thermal efficiency as shown in Table 2 and also in one of our previous investigations (Mwesigye et al., 2014a).

Table 2 Temperature gain and collector efficiency validation with experimental data from (Dudley et al., 1994)

\begin{tabular}{|c|c|c|c|c|c|c|c|c|c|c|c|}
\hline & $\begin{array}{c}\mathrm{DNI} \\
\left(\mathrm{W} / \mathrm{m}^{2}\right)\end{array}$ & $\begin{array}{l}\text { Wind } \\
\text { speed } \\
(\mathrm{m} / \mathrm{s})\end{array}$ & $\begin{array}{c}\text { Air } \\
\text { temperature } \\
\left({ }^{\circ} \mathrm{C}\right)\end{array}$ & $\begin{array}{c}\text { Flow } \\
\text { rate } \\
\text { (L/min) }\end{array}$ & $\begin{array}{l}T_{\text {inlet }} \\
\left({ }^{\circ} \mathrm{C}\right)\end{array}$ & $\begin{array}{c}\Delta T\left({ }^{\circ} \mathrm{C}\right) \\
\text { (Experimental) }\end{array}$ & $\begin{array}{l}\Delta T(C) \text { ) } \\
\text { (Present } \\
\text { study) }\end{array}$ & $\begin{array}{c}\% \text { ge } \\
\text { error } \\
\Delta T\end{array}$ & $\begin{array}{c}\text { Efficiency } \\
\text { (Experimental) }\end{array}$ & $\begin{array}{c}\text { Efficiency } \\
\text { (present } \\
\text { study) }\end{array}$ & $\begin{array}{l}\% \text { ge } \\
\text { error }\end{array}$ \\
\hline 1 & 933.7 & 2.6 & 21.2 & 47.70 & 102.2 & 21.80 & 22.11 & 1.44 & 72.51 & 72.78 & 0.37 \\
\hline 2 & 968.2 & 3.7 & 22.4 & 47.78 & 151.0 & 22.30 & 22.02 & -1.26 & 70.90 & 72.11 & 1.70 \\
\hline 3 & 982.3 & 2.5 & 24.3 & 49.10 & 197.5 & 22.00 & 21.26 & -3.36 & 70.17 & 70.61 & 0.63 \\
\hline 4 & 909.5 & 3.3 & 26.2 & 54.70 & 250.7 & 18.70 & 18.90 & 1.07 & 70.25 & 68.20 & -2.91 \\
\hline 5 & 937.9 & 1.0 & 28.8 & 55.50 & 297.8 & 19.10 & 17.71 & -7.28 & 67.98 & 62.65 & -7.85 \\
\hline 6 & 880.6 & 2.9 & 27.5 & 55.60 & 299.0 & 18.20 & 16.95 & -6.86 & 68.92 & 64.50 & -6.41 \\
\hline 7 & 920.9 & 2.6 & 29.5 & 56.80 & 379.5 & 18.10 & 17.39 & -3.92 & 62.34 & 58.48 & -6.19 \\
\hline 8 & 903.2 & 4.2 & 31.1 & 56.30 & 355.9 & 18.50 & 17.22 & -6.92 & 63.83 & 59.60 & -6.63 \\
\hline
\end{tabular}




\subsection{Heat flux distribution and intercept factor}

For a rim angle of $80^{\circ}$ and a concentration ratio of 86 considered in this study, the heat flux distribution on the receiver's absorber tube at different slope errors and a specularity error of 0 mrad and 3 mrad is shown in Fig. 8(a) and 8(b) respectively. As shown in these figures, the presence of slope errors affects the heat flux distribution on the receiver's absorber tube significantly. Also shown, is that the heat flux peak reduces as the slope error increases. This is because the rays reflected from the reflector are no longer specularly reflected but randomly reflected to different points on the receiver's absorber tube. Additionally, with the presence of slope errors, some of the rays will not be intercepted by the receiver tube. Since some rays will miss the receiver tube, the average heat flux on the absorber tube is shown to be significantly lower at higher values of slope errors. For example, at a specularity error of $0 \mathrm{mrad}$, the average absorber tube heat flux is $44,380 \mathrm{~W} / \mathrm{m}^{2}, 43,560 \mathrm{~W} / \mathrm{m}^{2}, 42,360 \mathrm{~W} / \mathrm{m}^{2}, 40,915 \mathrm{~W} / \mathrm{m}^{2}$, $39,170 \mathrm{~W} / \mathrm{m}^{2}$ and $36,540 \mathrm{~W} / \mathrm{m}^{2}$ at slope errors of $0 \mathrm{mrad}, 1 \mathrm{mrad}, 2 \mathrm{mrad}, 3 \mathrm{mrad}, 4 \mathrm{mrad}$ and $5 \mathrm{mrad}$, respectively.

As shown in Fig. 8(a) and 8(b) the variation of heat flux with specularity error is not so significant at the low values of specularity errors considered in this study. However, the average heat flux is shown to slightly reduce as the specularity error changes from $0 \mathrm{mrad}$ to $3 \mathrm{mrad}$. The influence of the specularity error on the heat flux distribution is shown in Fig. 9 for a slope error of $3 \mathrm{mrad}$. As shown, the change in mirror specularity does not alter the heat flux distribution significantly at any given value of the slope error. However, there is a slight reduction in the average heat flux on the receiver's absorber tube as the specularity error increases, especially in areas close to the lower half of the receiver's absorber tube $\left(-90^{\circ} \leq \theta \leq 10^{\circ}\right)$. Generally, at 


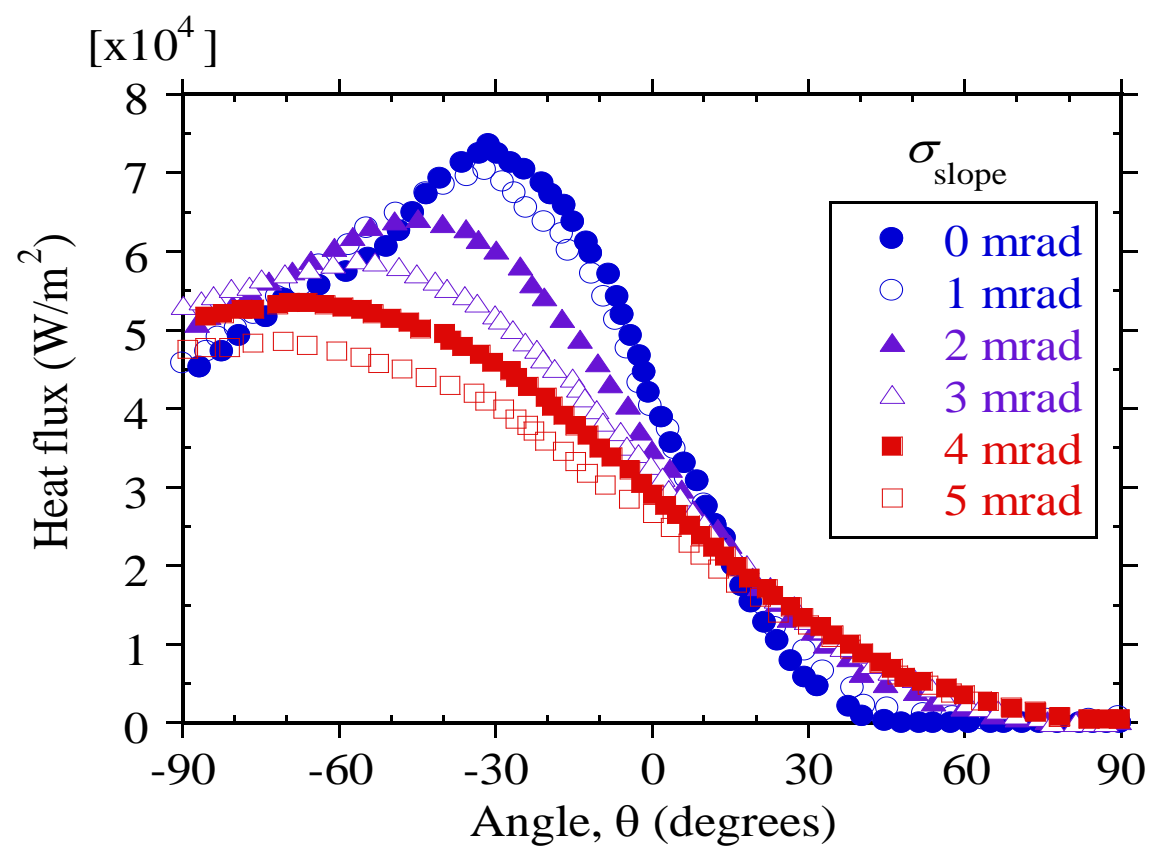

(a)

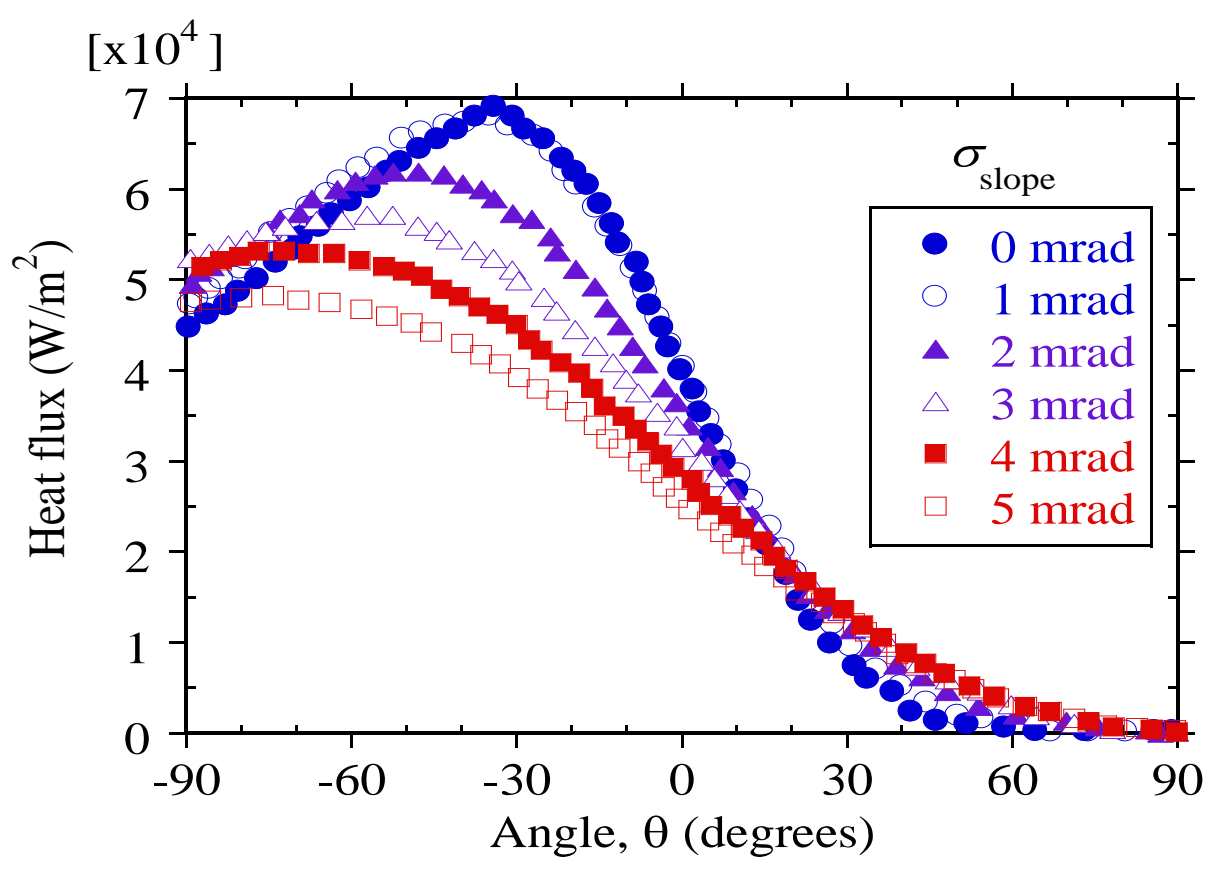

(b)

Fig. 8 Heat flux as a function of absorber tube circumferential angle and slope errors for specularity error of: (a) 0 mrad (b) $3 \mathrm{mrad}$ 


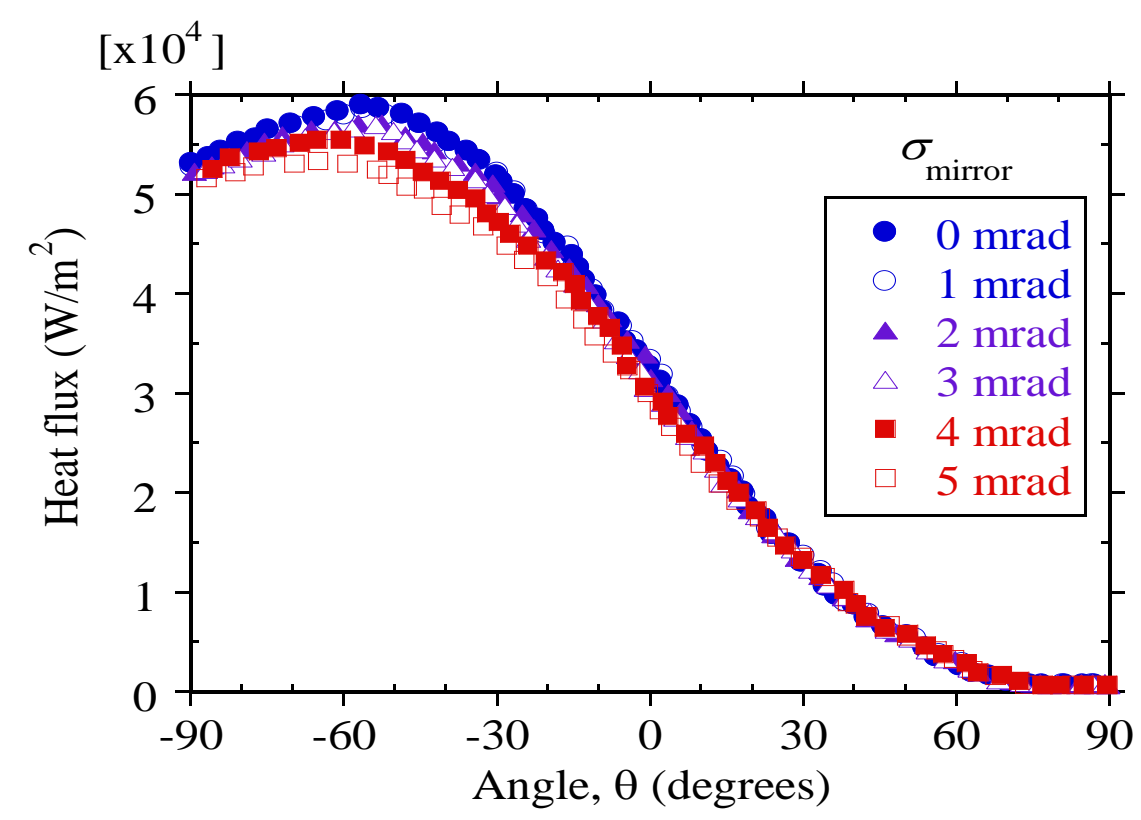

(b)

Fig. 9 Heat flux as a function of absorber tube circumferential angle and specularity error at a slope error of $3 \mathrm{mrad}$

different combinations of slope errors and specularity errors, the heat flux on the receiver's absorber tube is non-uniform with high heat flux peaks at lower values of slope errors.

To characterise the optical performance of the parabolic trough collector system, the optical efficiency given in Eq. (1) was used. For normal incidence, the remaining factor influencing the optical efficiency is the intercept factor. This is a measure of the fraction of the number of the rays reflected by the collector that will be intercepted by the receiver. A value of 1 means that all rays from the collector are intercepted and a value of zero would mean that none of the rays reflected by the collector are intercepted. Fig. 10 (a) shows the intercept factor as a function of specularity error at different slope errors. As shown, the intercept factor decreases significantly as the slope errors increase. At a specularity error of $0 \mathrm{mrad}$, the intercept factor reduces by 


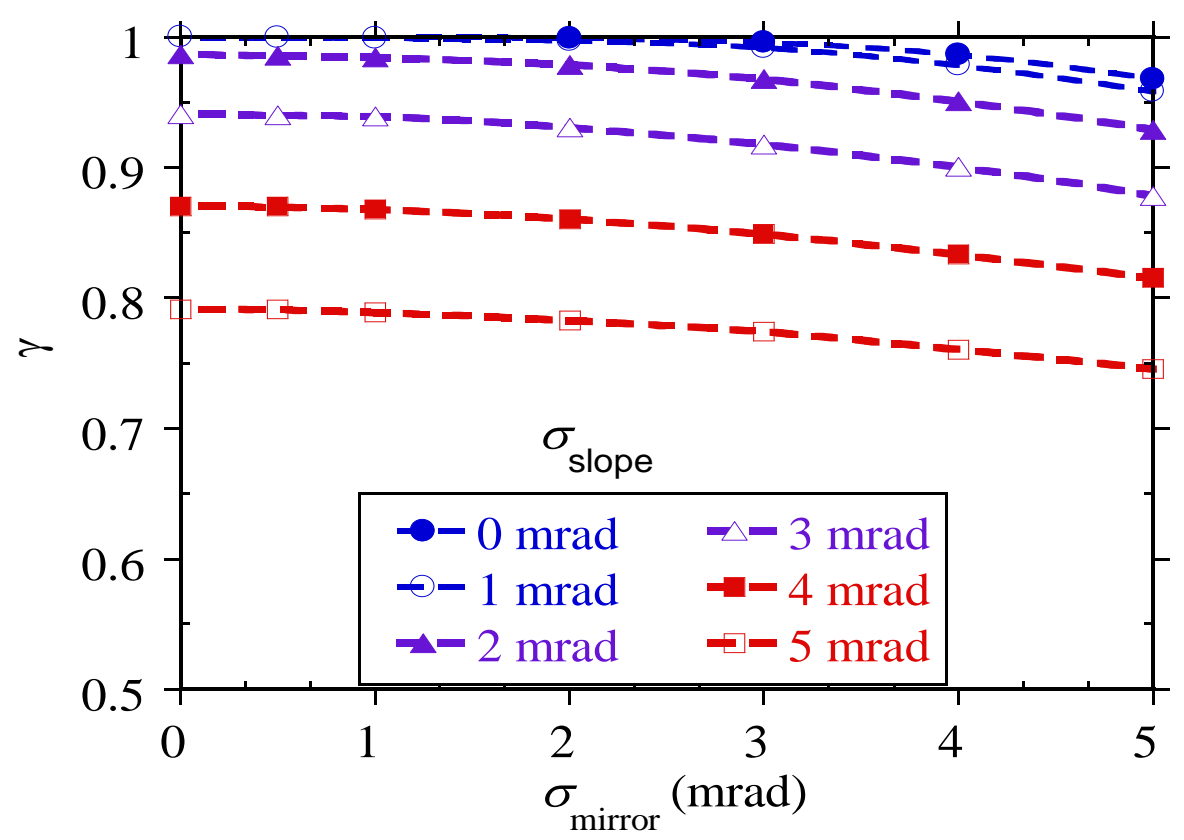

(a)

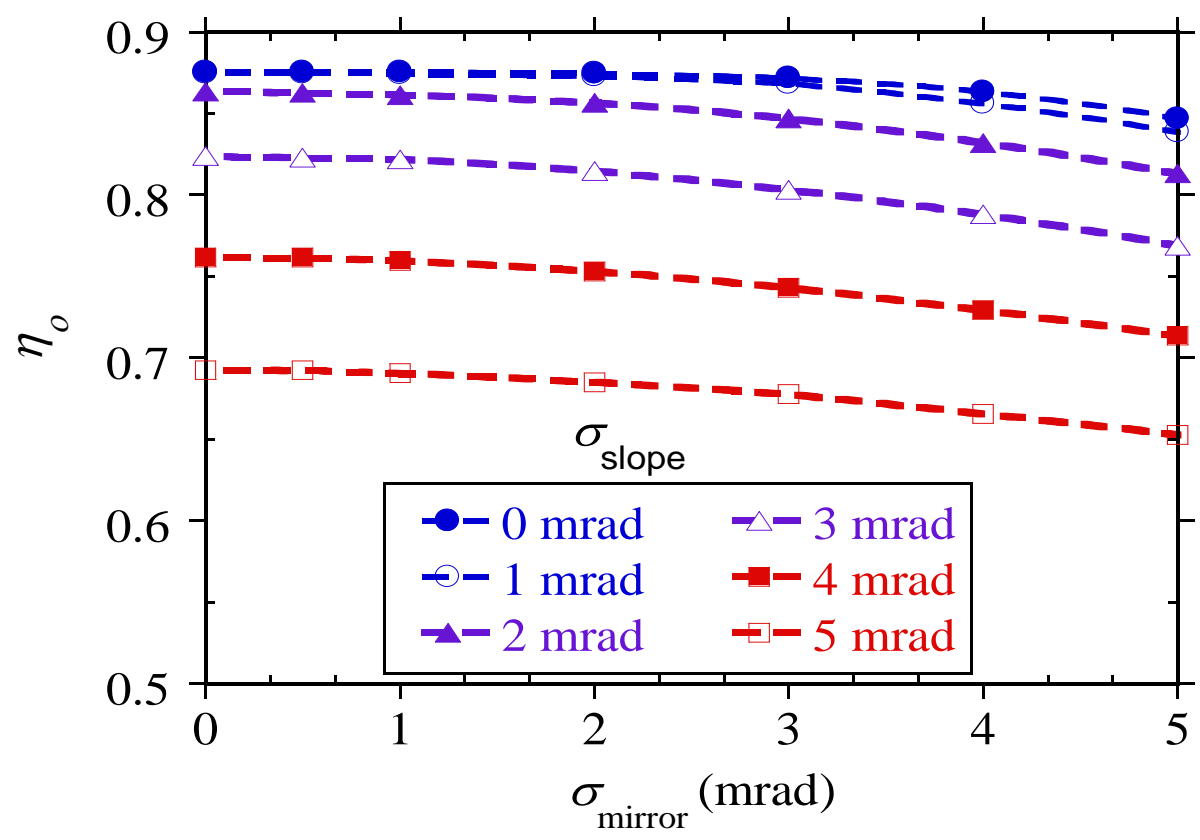

Fig. 10 Optical performance of a parabolic trough system with a rim angle of $80^{\circ}$ and concentration ratio 86 (a) Intercept factor as a function of specularity errors and slope errors, and (b) Optical efficiency as a function of specularity errors and slope errors 
about $21 \%$ as the slope error increases from 0 to $5 \mathrm{mrad}$. The same reduction is noted at a specularity error of $5 \mathrm{mrad}$ as the slope error increases from 0 to $5 \mathrm{mrad}$. As shown in the figure, specularity errors do not significantly affect the intercept factor compared with the effect of slope errors. This is in line with the previous discussion that the heat flux distribution and average heat flux on the absorber tube are not significantly influenced as the specularity error increases.

At a given slope error, there is only a slight reduction in the intercept factor as the specularity error increases. For example, at a slope error of $3 \mathrm{mrad}$, the intercept factor reduces by $1 \%$ as the specularity error increases from 0 to $2 \mathrm{mrad}$ and by $6 \%$ as the specularity error increases from 0 to $5 \mathrm{mrad}$. Significant reductions in the intercept factor are noted as the specularity error increases to more than 4 mrad. Fig. 10 (b) depicts the variation of the system optical efficiency with specularity error at different values of slope error. The same trend as was shown by the intercept factor exists since according to Eq. (1), with constant material properties, the optical efficiency is mainly affected by the optical errors through the intercept factor. This same trend was presented by Gee et al., (2010).

\subsection{Receiver thermal performance}

Studies on the thermal performance of parabolic trough receivers have shown that the heat flux distribution on the receiver has a notable effect on the receiver's thermal and thermodynamic performance (Mwesigye et al., 2014b, He et al., 2011, Lu et al., 2013). The heat flux distribution is also expected to affect the temperature distribution in the receiver's absorber tube. Fig. 11 shows the temperature distribution in the receiver's absorber tube at a flow rate of $30.8 \mathrm{~m}^{3} / \mathrm{h}$ (a heat transfer inlet velocity of $2.5 \mathrm{~m} / \mathrm{s}$ ). This is close to values in typical plants and close to values considered in the study by Forristall (2003) i.e. heat transfer fluid inlet velocity of $2.58 \mathrm{~m} / \mathrm{s}$ (or 140 


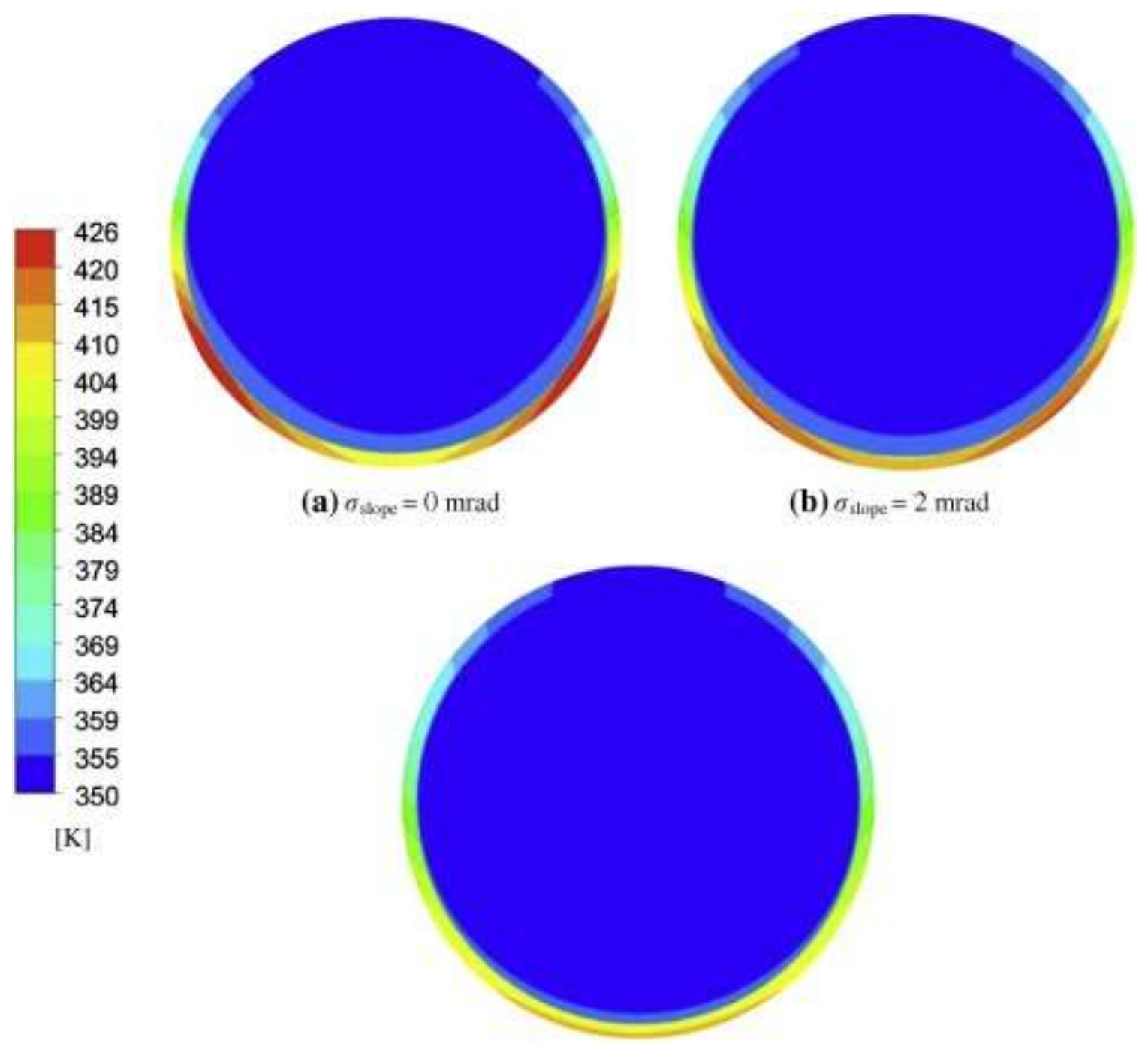

(c) $\sigma_{\text {slope }}=4 \mathrm{mrad}$

Fig. 11 Temperature contours of the absorber tube outlet at a flow rate of $30.8 \mathrm{~m}^{3} / \mathrm{h}$, inlet temperature of $350 \mathrm{~K}$, specularity error of $0 \mathrm{mrad}$ and slope errors of (a) $\sigma_{\text {slope }}=0 \mathrm{mrad}$,

(b) $\sigma_{\text {slope }}=2 \mathrm{mrad}$, and (c) $\sigma_{\text {slope }}=4 \mathrm{mrad}$

gpm $=31.8 \mathrm{~m}^{3} / \mathrm{h}$ ). As shown in Fig. 11, the temperature gradients in the receiver's absorber tube are significantly higher at low values of slope errors. This follows from the variation of heat flux with slope errors shown in Fig. 8. The presence of slope errors reduces the peak heat flux as well as the average heat flux received on the absorber tube, thus, low absorber tube temperature 


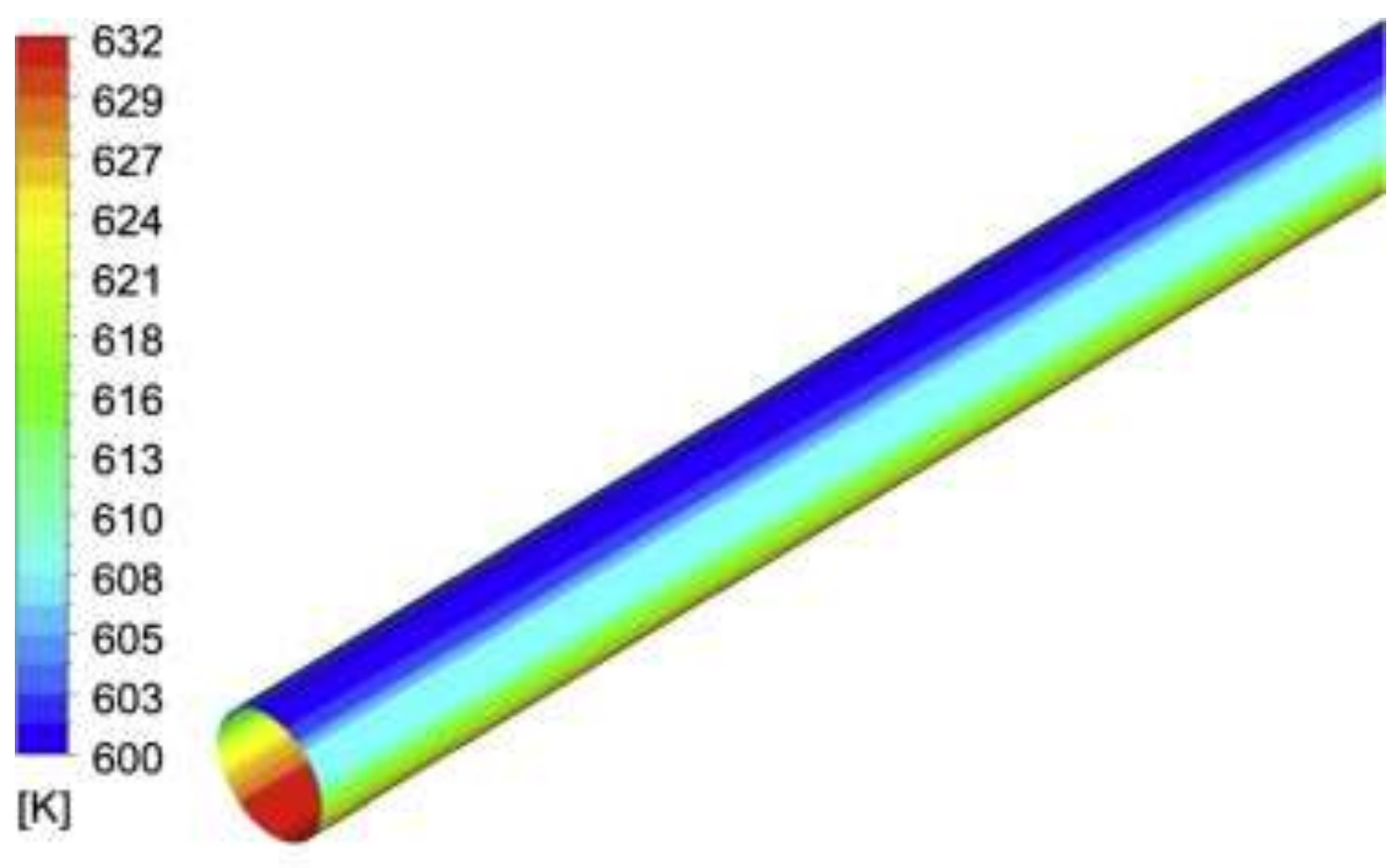

(a)
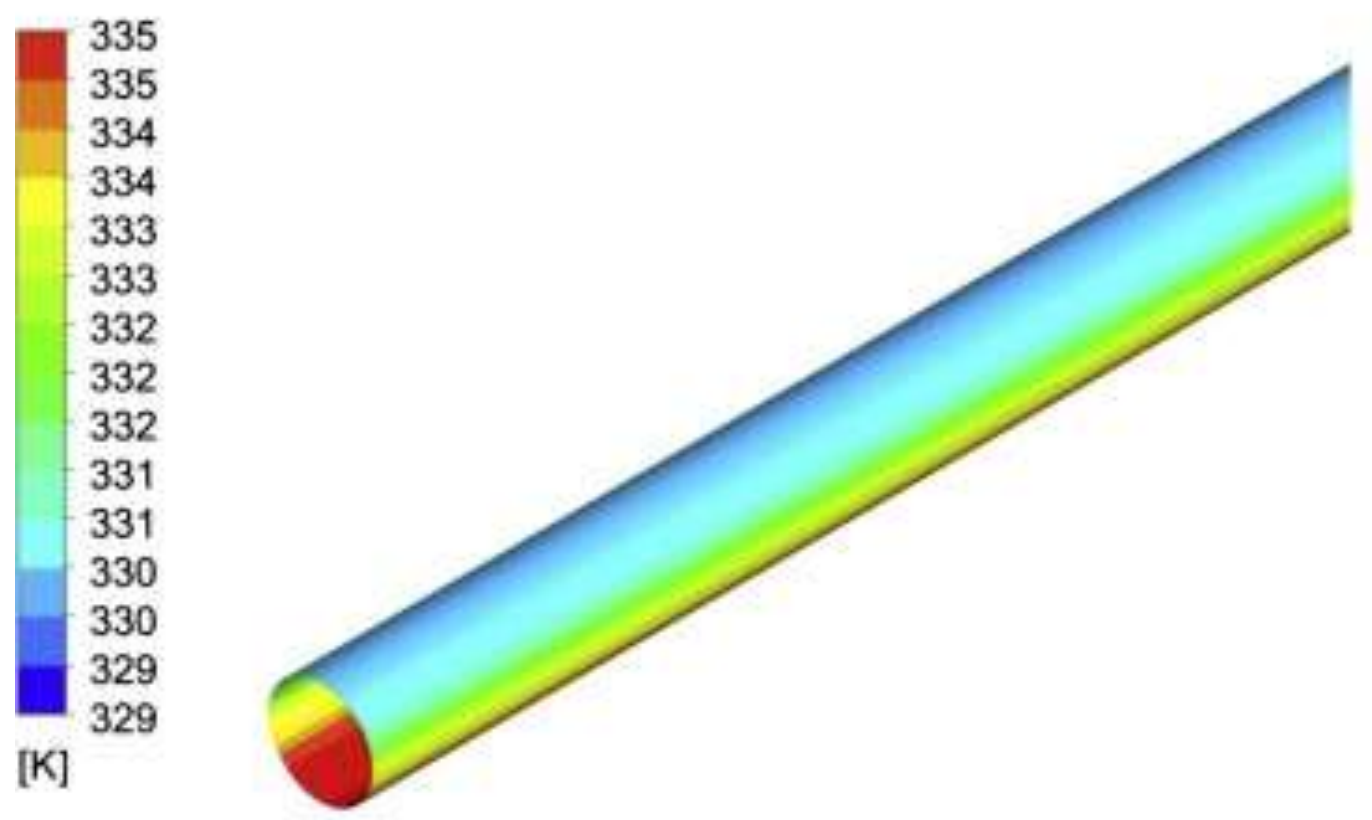

(b)

Fig. 12 Temperature distribution in the receiver tube at a flow rate of $30.8 \mathrm{~m}^{3} / \mathrm{h}$ an inlet temperature of $600 \mathrm{~K}$, specularity error of $0 \mathrm{mrad}$ and a slope error of $4 \mathrm{mrad}$. (a) Contours of absorber tube temperature, and (b) Contours of receiver glass cover temperature 
gradients as well as low average absorber tube temperatures as slope errors increase. It is also shown in Fig. 11, that due to the non-uniform heat flux distribution, the heat transfer fluid will be hotter in the lower half of the absorber tube where concentrated heat flux is received than in the top half where only direct normal radiation is received. This trend was also shown by (Muñoz and Abánades, 2011). The temperature distribution in the receiver's glass cover follows the same trend as that in the receiver's absorber tube. As shown in Fig. 12, the areas of high absorber tube temperatures correspond to areas of high temperature on the receiver's glass cover. At the slope error of $3 \mathrm{mrad}$, a specularity error of $0 \mathrm{mrad}$ and an inlet temperature of $600 \mathrm{~K}$, the absorber tube temperature gradient is about $32 \mathrm{~K}$, the glass cover temperature gradient is about $6 \mathrm{~K}$ and the average glass cover temperature is about $332 \mathrm{~K}$ or $50^{\circ} \mathrm{C}$ when the flow rate is $30.8 \mathrm{~m}^{3} / \mathrm{h}$. For flow rates greater than $30.8 \mathrm{~m}^{3} / \mathrm{s}$, the maximum average glass cover temperature is about $78^{\circ} \mathrm{C}$ at the highest inlet temperature considered in this study of $650 \mathrm{~K}$.

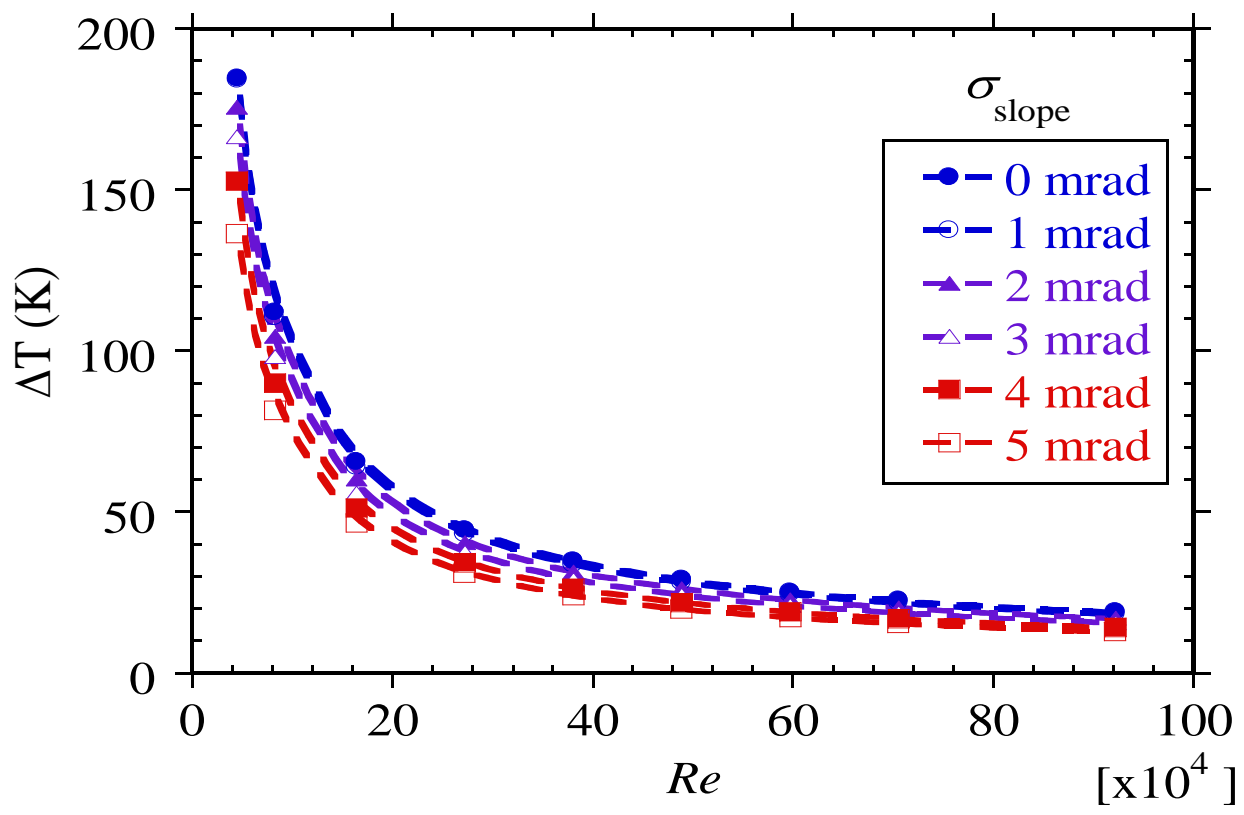

Fig. 13 Absorber tube circumferential temperature gradient as a function of Reynolds number and slope error at an inlet temperature of $600 \mathrm{~K}$ and specularity error of $0 \mathrm{mrad}$ 
Fig. 13 shows the variation of absorber tube circumferential temperature gradients (difference between maximum and minimum absorber tube temperatures) with Reynolds numbers and slope errors for an inlet temperature of $600 \mathrm{~K}$. As expected, the absorber tube circumferential temperature gradients are shown to reduce as the slope errors increase. This is in line with the previous discussion where peak heat flux on the absorber tube and thus temperature gradients were shown to reduce as slope errors increased. The largest absorber tube circumferential temperature gradients exist at the lowest Reynolds number and lowest slope error. The reduction in the absorber tube circumferential temperature gradients as Reynolds numbers increase is due to the increase in heat transfer performance as Reynolds numbers increase. The presence of higher circumferential temperature gradients at low values of slope errors is in line with the variation of the heat flux on the absorber tube at different slope errors. As discussed earlier, with low slope errors, most reflected sun rays will be intercepted by the receiver and higher heat flux peaks are expected. The circumferential temperature gradient is about $184 \mathrm{~K}$ when the inlet temperature is $600 \mathrm{~K}$, the Reynolds number is $4.5 \times 10^{4}$ (flow rate of $4.93 \mathrm{~m}^{3} / \mathrm{hr}$ or heat transfer fluid inlet velocity of $0.4 \mathrm{~m} / \mathrm{s}$ ) and slope error is $0 \mathrm{mrad}$. The temperature gradients reduce as the Reynolds numbers and slope errors increase.

Generally, the receiver circumferential temperature gradients become lower than $50 \mathrm{~K}$ for Reynolds numbers greater than $2.7 \times 10^{5}$ (flow rate of $30.8 \mathrm{~m}^{3} / \mathrm{h}$ or inlet velocity of $2.5 \mathrm{~m} / \mathrm{s}$ ) at all values of slope errors and specularity errors at an inlet temperature of $600 \mathrm{~K}$. The temperature gradients at $30.8 \mathrm{~m}^{3} / \mathrm{h}$ and an inlet temperature of $600 \mathrm{~K}$ for different slope errors are about $44 \mathrm{~K}$ at a slope error of $0 \mathrm{mrad}, 40 \mathrm{~K}$ at a slope error of $2 \mathrm{mrad}, 37 \mathrm{~K}$ at a slope error of $3 \mathrm{mrad}$ and 32 $\mathrm{K}$ at a slope error of $4 \mathrm{mrad}$ when the specularity error is $0 \mathrm{mrad}$. For all the inlet temperatures 


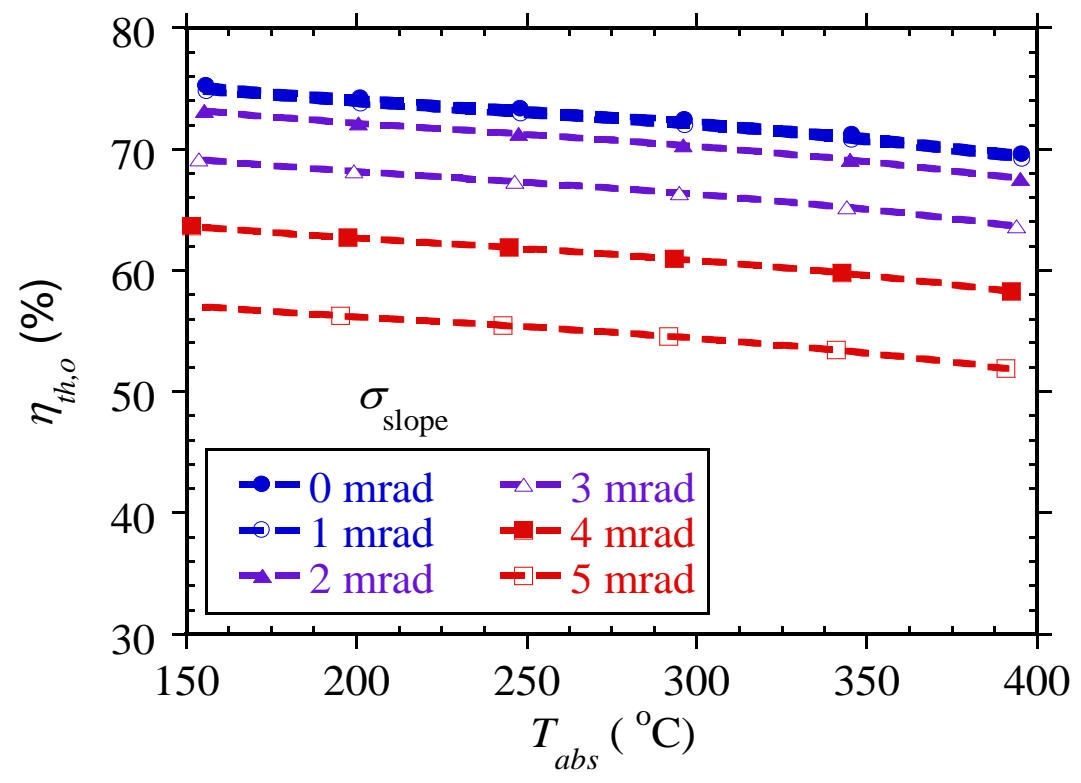

(a)

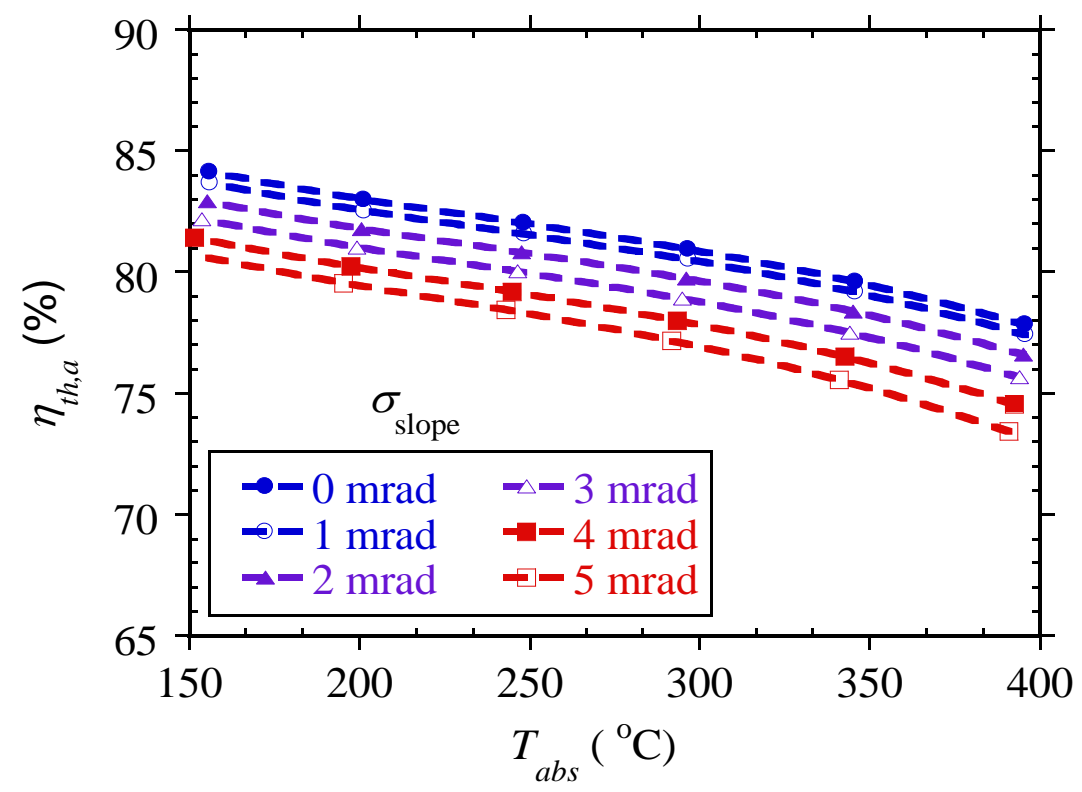

(b)

Fig. 14 Collector thermal efficiency as a function of average absorber tube temperature and slope error at a specularity error of $0 \mathrm{mrad}$ and a flow rate of $30.8 \mathrm{~m}^{3} / \mathrm{h}$ (a) Overall thermal efficiency, and (b) thermal efficiency based on the absorbed solar radiation. 
considered, flow rates greater than $30.8 \mathrm{~m}^{3} / \mathrm{h}$ ensured temperature gradients less than $50 \mathrm{~K}$, a value needed for safe operation of the receiver (Wang et al., 2013, Eck and Steinmann, 2002). The specularity errors are expected to have an insignificant effect on the temperature gradient since they do not significantly alter the distribution of heat flux on the receiver's absorber tube.

The overall thermal efficiency of the parabolic trough system is given by Eq. (9a). As the slope errors increase, the useful heat delivered by the receiver and consequently the overall thermal efficiency will be affected. Fig. 14 (a) shows the overall thermal efficiency of the parabolic trough system as a function of the absorber tube temperature and slope errors. As expected, the overall thermal efficiency reduces as the slope errors increase. An increase in the slope errors also means that less of the sun's rays incident on the collector are intercepted by the receiver, thus, lower values of overall thermal efficiency at high values of the slope error. The overall thermal efficiency is also shown to reduce as the absorber tube temperature increases. This is expected since higher absorber tube temperatures mean a higher radiation heat loss between the absorber tube and the glass envelope which is increased further owing to the increased emissivity of the absorber tube as the temperatures increase and therefore a much higher receiver thermal loss. At a given absorber tube temperature or Reynolds number, the overall thermal efficiency reduces between $16 \%-17 \%$ as the slope errors increase from $0 \mathrm{mrad}$ to $5 \mathrm{mrad}$. Figure 14(b) shows the thermal efficiency based on the absorbed solar radiation $\left(\eta_{t h, a}\right)$ given by Eq. (9b), the same trend as the overall thermal efficiency is obtained, but the effect of slope errors is not as pronounced as was seen in Figure 14(a). Moreover, the thermal efficiency based on absorbed solar radiation is also generally higher than the overall thermal efficiency. This is expected since the thermal efficiency based on the absorbed solar radiation does not take into account the optical losses of the system. The reduction in the thermal efficiency based on the absorbed solar 
radiation as the slope error increases is probably due to the lower useful energy delivered as the slope errors decrease.

A comparison of receiver overall thermal efficiency for three different approaches used to represent heat flux distribution on the receiver's absorber tube is shown in Table 3. The first approach is the one described in this study where the heat flux is non-uniform as determined using ray tracing. In the second approach a uniform heat flux around the receiver's absorber tube is used. The value of the heat flux used here is the average of the non-uniform heat flux distribution obtained in the first approach. For example at a slope error of 3 mrad and a specularity error of $3 \mathrm{mrad}$ the average heat flux was $33585 \mathrm{~W} / \mathrm{m}^{2}$. In the third approach, a concentrated heat flux is applied on the lower half of the receiver tube and a direct normal irradiance value on the upper half of the absorber tube. This approach is similar to the one used by Muñoz and Abánades (2011). As shown In Table 3, using a uniform heat flux over predicts the performance of the receiver by about $13 \%$ while using a concentrated heat flux profile on the absorber tube's lower half under predicts the overall thermal efficiency about to $7 \%$ compared with a model that uses an actual non-uniform heat flux profile. The deviations between the three approaches are likely due to the fact that using approximate uniform heat flux profiles will likely give different values of the useful energy gain by the heat transfer fluid and also different values of the receiver thermal losses compared with the case when the non-uniform heat flux is considered. 
Table 3. Comparison of different approaches for representing heat flux on the receiver's absorber tube at an inlet temperature of $600 \mathrm{~K}$, slope error of $3 \mathrm{mrad}$ and specularity error of $3 \mathrm{mrad}$

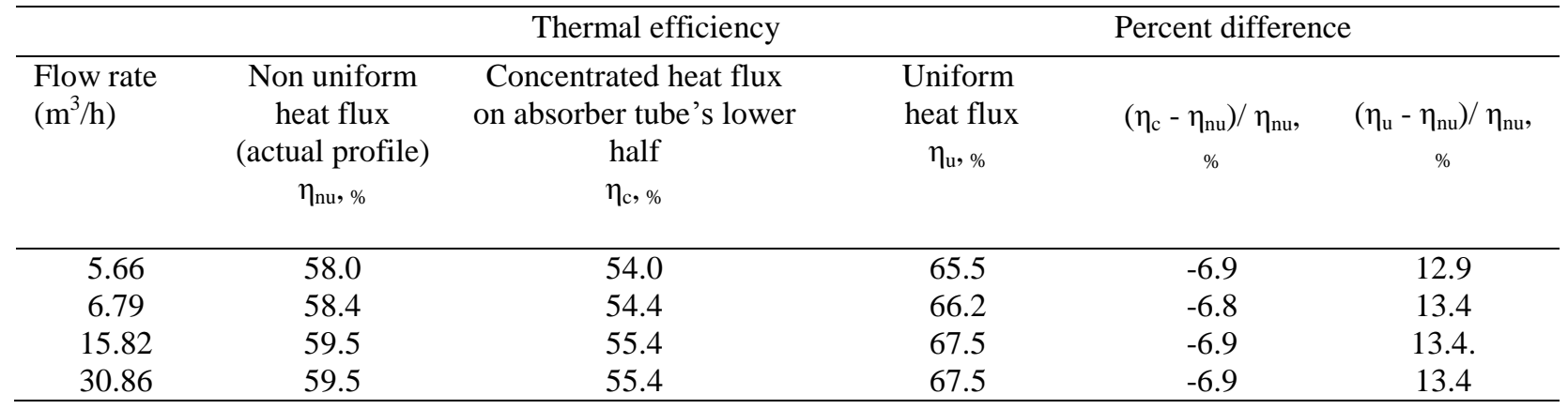

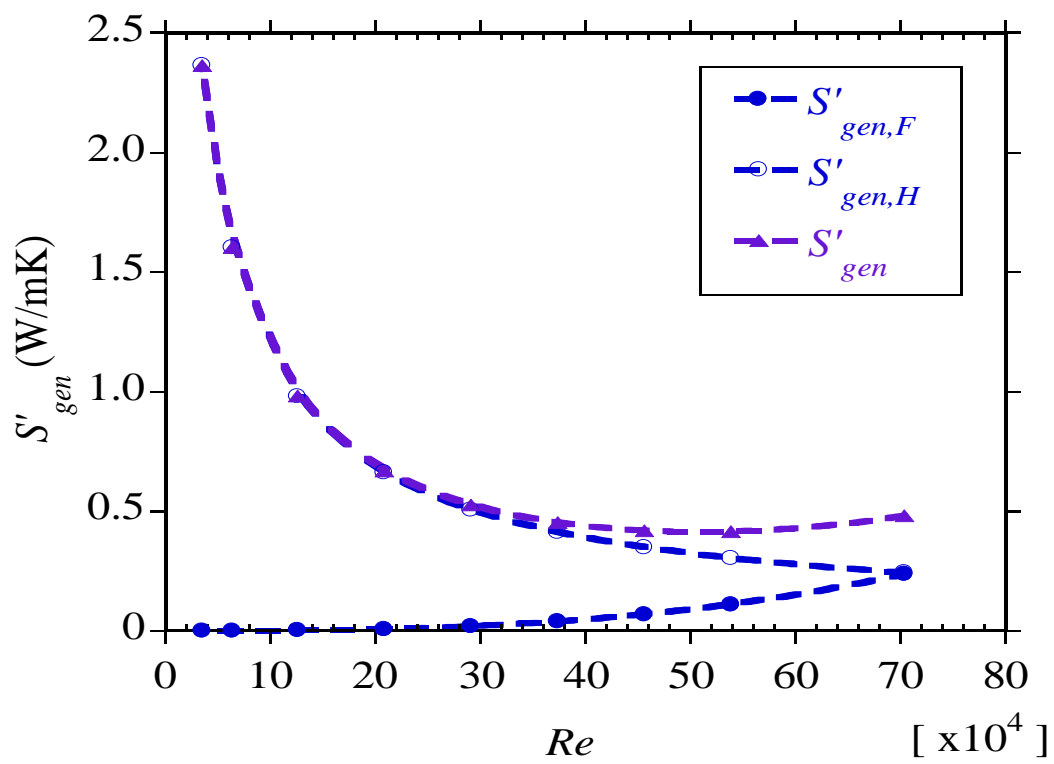

Fig. 15 Fluid friction irreversibility, heat transfer irreversibility and total entropy generation rate as a function of Reynolds number at a slope error of $0 \mathrm{mrad}$, specularity error of $0 \mathrm{mrad}$ and inlet temperature of $550 \mathrm{~K}$

\subsection{Receiver thermodynamic performance}

The thermodynamic performance of the receiver is based on the entropy generation minimisation method. In this method, the entropy generation rates are obtained and conditions as well as parameters that give the lowest entropy generation rates are considered thermodynamically better. In this study, the entropy generation rates of interest are the ones due to fluid friction 
irreversibility and heat transfer irreversibility in the receiver and were obtained using Eqs. (24) and (25). These two irreversibilities are always conflicting - as one increases, the other reduces. The heat transfer irreversibility is the dominant source of irreversibility at low Reynolds numbers, it reduces as the Reynolds numbers increase owing to the increased heat transfer performance and the subsequent reduction in the absorber tube finite temperature difference as Reynolds numbers increase. On the other hand, the fluid friction irreversibility is very small at low Reynolds numbers, it increases with increasing Reynolds and becomes the dominant source of irreversibility at high Reynolds numbers. This trend was also obtained in this work as illustrated in Fig. 15. Also from Fig. 15, there is an optimal Reynolds number for which the entropy generation rate becomes minimum, after which the entropy generation rate increases as the Reynolds numbers increase.

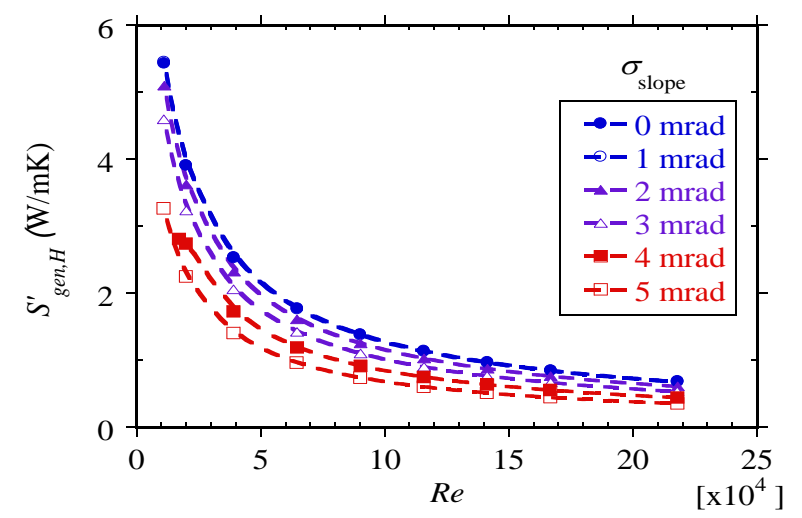

(a)

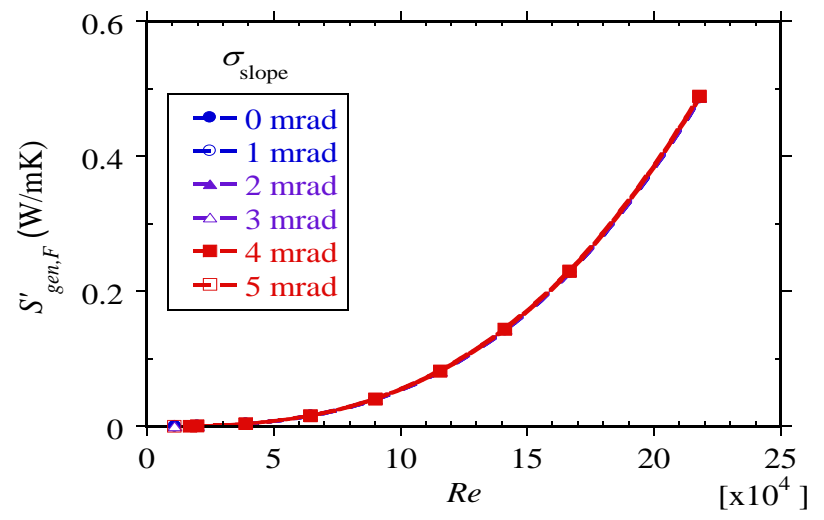

(b)

Fig. 16 Entropy generation as a function of Reynolds number and slope error for a specularity error of 0 mrad and temperature of $400 \mathrm{~K}$ : (a) entropy generation due to heat transfer irreversibility (b) entropy generation due to fluid friction irreversibility 
Figures 16(a) and 16(b) show the influence of slope errors on the fluid friction irreversibility and heat transfer irreversibility, respectively. It is clear that the heat transfer irreversibility reduces with increase in the Reynolds number and increase in the slope error. The fluid friction irreversibility increases with Reynolds number and is not affected by the presence of slope errors. Thus, as the collector slope errors change, only the heat transfer irreversibility is affected and will contribute to the change in the total entropy generation rate. The contribution of each irreversibility to the total entropy generation rate can additionally be illustrated by the Bejan

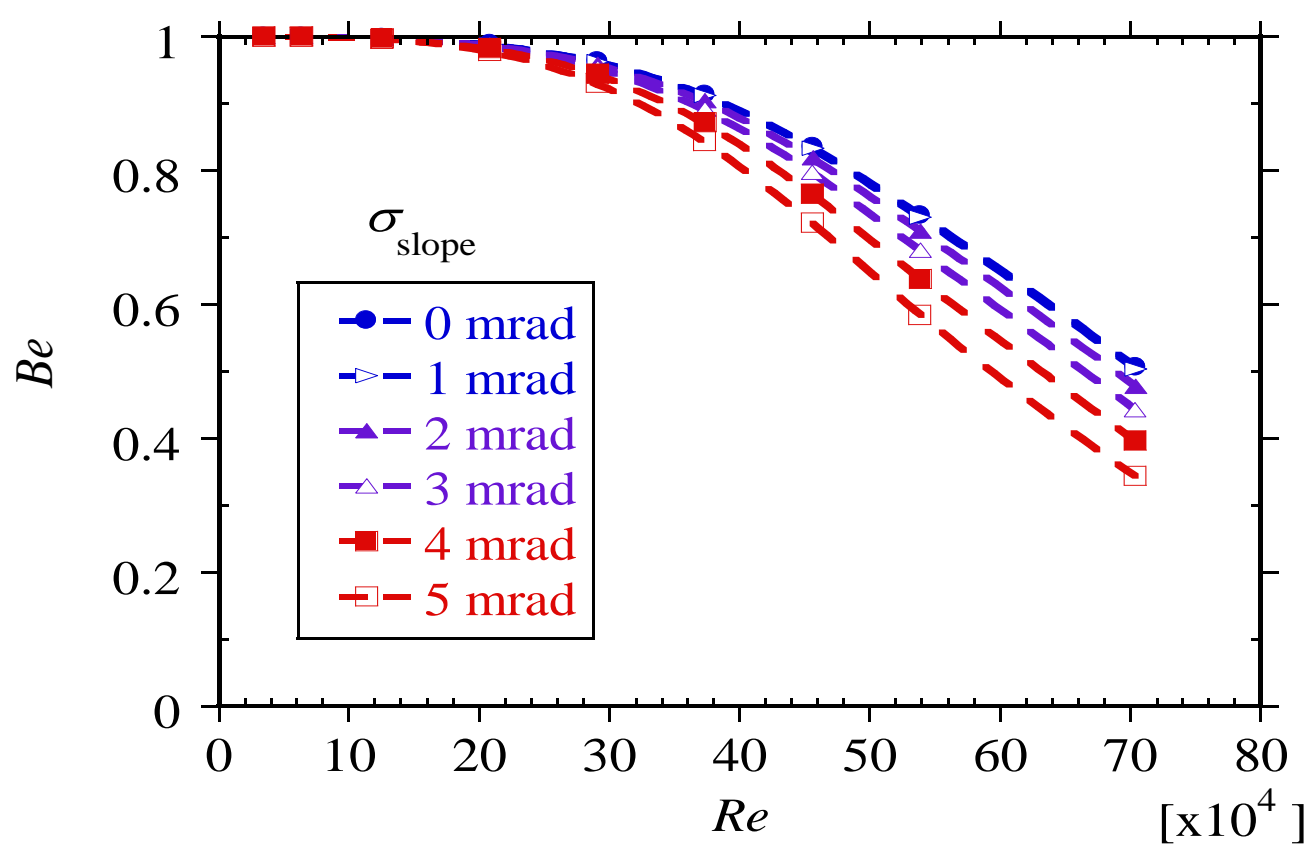

Fig. 17 Bejan number as a function of Reynolds number and slope error at an inlet temperature of $550 \mathrm{~K}$ and a specularity error of $0 \mathrm{mrad}$ 


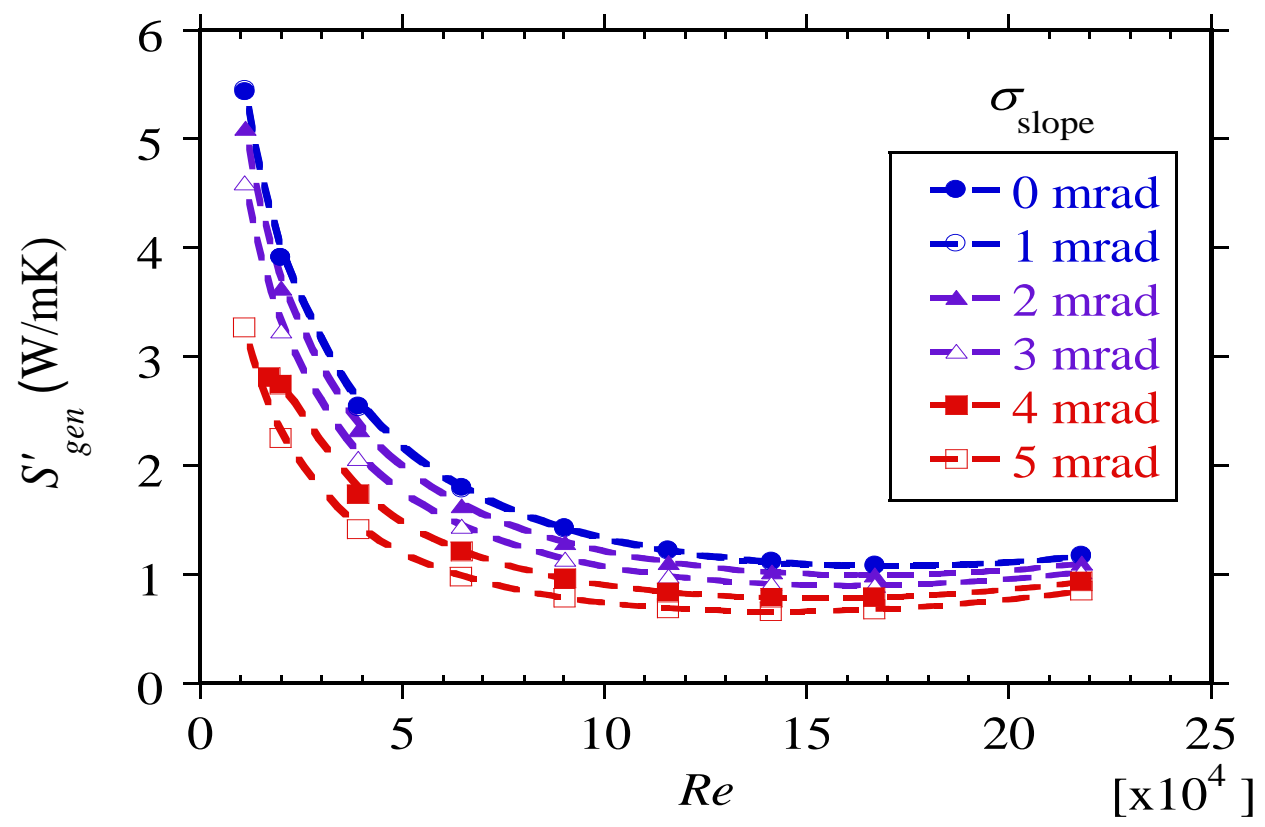

(a)

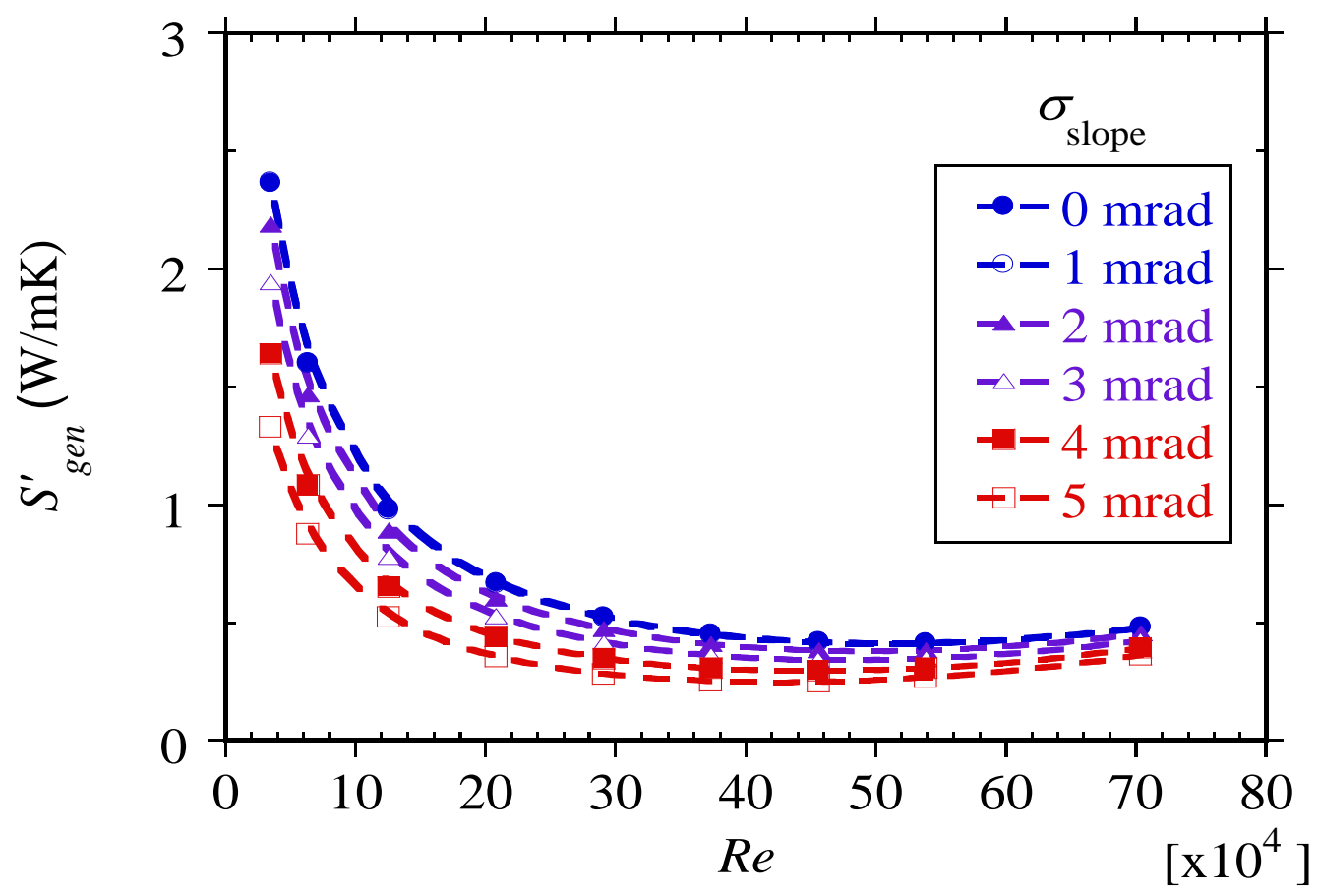

(b)

Fig. 18 Entropy generation as a function of Reynolds number and slope error for a specularity error of 0 mrad (a) temperature of $400 \mathrm{~K}$ and (b) temperature of $550 \mathrm{~K}$ 
number, which is the ratio of the heat transfer irreversibility to the total entropy generation rate. As shown in Fig. 17, the Bejan number reduces with increasing slope errors and Reynolds numbers. The reduction in the heat transfer irreversibility as the slope error reduces is mainly due to the influence of slope errors on the heat flux distribution on the receiver's absorber tube. With the reduction in heat flux peaks as the slope errors increase, the absorber tube circumferential temperature gradients reduce thereby reducing the heat transfer irreversibility.

Figure 18(a) and 18(b) show the variation of the total entropy generation rate with Reynolds number and slope errors at specularity errors of $0 \mathrm{mrad}$ and fluid inlet temperatures of $400 \mathrm{~K}$ and $550 \mathrm{~K}$. The total entropy generation rates are shown to reduce as slope errors increase. As already discussed, this is due to the reduction in the heat flux peaks and consequently the absorber tube temperature gradients as the slope errors increase. A closer look at the figures also shows the presence of an optimal Reynolds number for which the entropy generation is a minimum. Beyond this, the entropy generation rates increase as the Reynolds number increases. This result is due to the variation of the fluid friction irreversibility and the heat transfer irreversibility already presented. The heat transfer irreversibility decreases as the Reynolds number increases, while the fluid friction irreversibility increases as the Reynolds number increases. It is this variation that results in a Reynolds number at which the entropy generation rate is a minimum. 


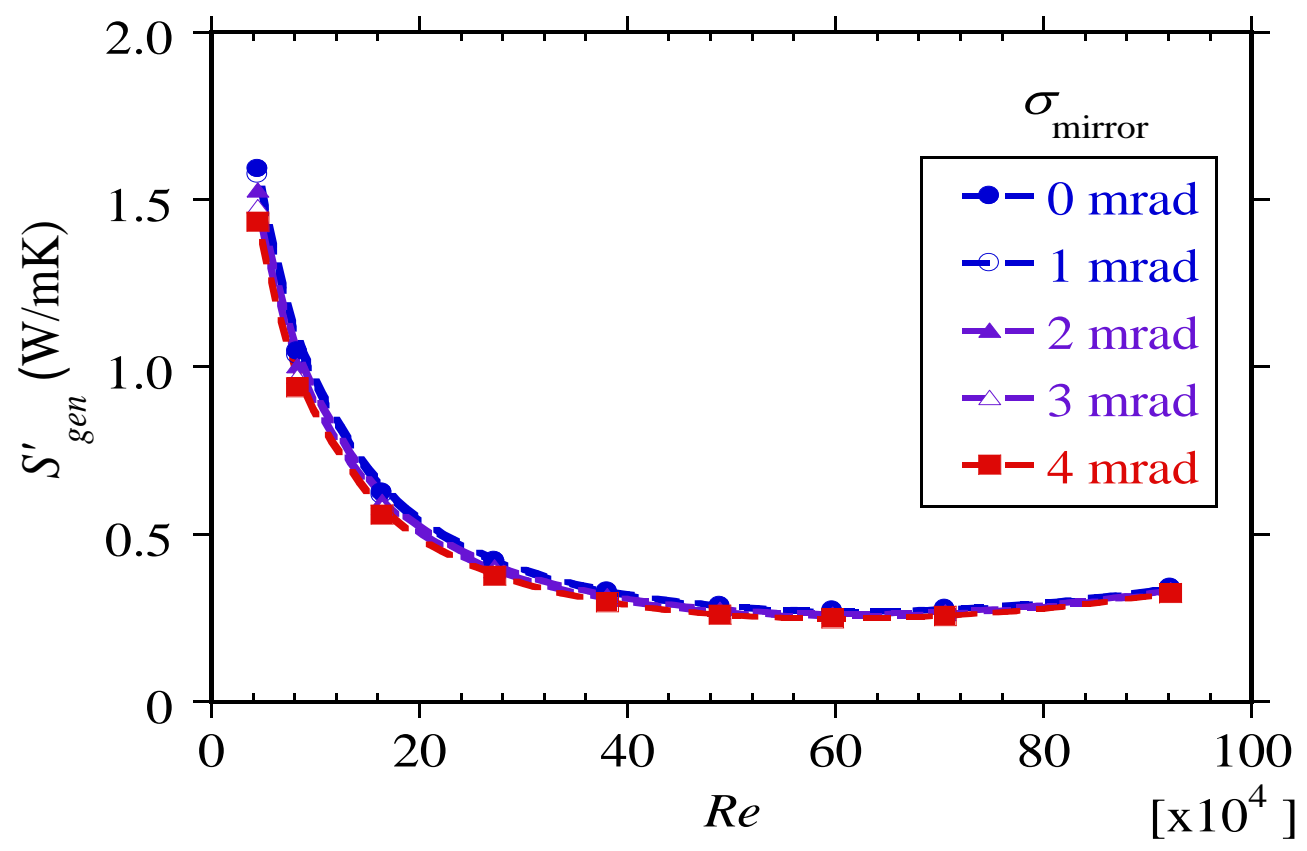

Fig. 19 Entropy generation as a function of Reynolds number and specularity error at a slope error of $3 \mathrm{mrad}$ and inlet temperature of $600 \mathrm{~K}$

As shown in Fig. 19, the specularity errors do not significantly affect the entropy generation rates in the parabolic receiver. This follows from the previous discussion on heat flux distribution on the receiver's absorber tube where it was shown that specularity errors do not affect the heat flux distribution and subsequently the absorber tube temperature distribution significantly.

From the entropy generation analysis, it appears that using collectors with higher slope errors is beneficial. Yet, from the first law of thermodynamics and consideration of the effect of slope errors on the system's thermal efficiency shows that the performance degrades as slope errors increase. To clearly show the influence of slope errors on receiver performance, the exergy transferred from the receiver to the point-of-use was used. In effect, both the first law and second law are combined. The flow rate of exergy can be obtained as 


$$
\dot{E}_{T}=\dot{m}\left[\left(h_{\text {oultet }}-h_{\text {inlet }}\right)-T_{o}\left(s_{\text {oultet }}-s_{\text {inlet }}\right)\right]
$$

Where the change in enthalpy is $h_{\text {outlet }}-h_{\text {inlet }}=C_{p}\left(T_{\text {outlet }}-T_{\text {inlet }}\right)$ in which $C_{p}$ is the specific heat capacity evaluated at the average temperature between the outlet and inlet. The change in specific entropy is $s_{\text {outlet }}-s_{\text {inlet }}$ is also the specific entropy generated $\left(S_{g e n} / \dot{m}\right)$ as the fluid flows through the receiver and $T_{o}$ is the ambient temperature taken as $300 \mathrm{~K}$, such that

$\dot{E}_{T}=\dot{m} C_{p}\left(T_{\text {outlet }}-T_{\text {inlet }}\right)-T_{o} S_{\text {gen }}$

$S_{\text {gen }}$ is determined using Eqs. (24) - (25). The second term in Eq. (33), $T_{o} S_{\text {gen }}$ is known as the exergy destruction rate $\left(\dot{E}_{D}\right)$ according to the Gouy-Stodola theorem. This is the work lost due to irreversibilities.

Figure 20(a) and 20(b) show the variation of the exergy flow rate per unit receiver length $\left(\dot{E}_{T}^{\prime}\right)$ and the exergy destruction rate per unit receiver length $\left(\dot{E}_{T}^{\prime}\right)$ as functions of Reynolds number at different values of slope errors, a specularity error of $0 \mathrm{mrad}$ and temperatures of $600 \mathrm{~K}$ and 650 


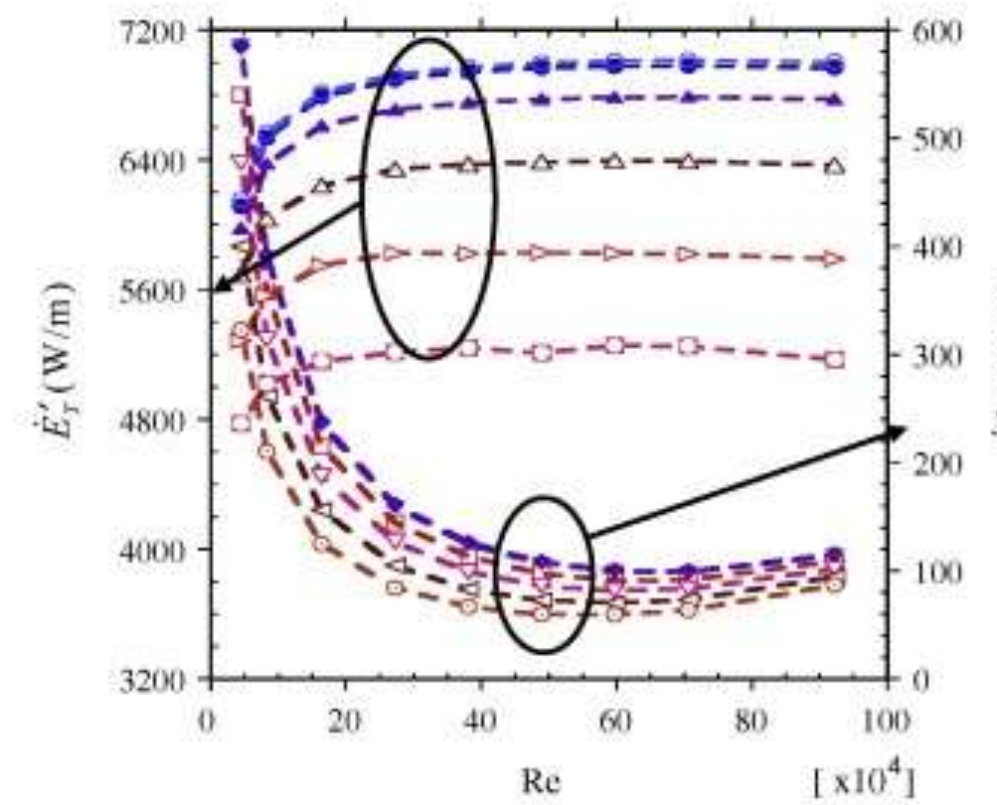

(a)

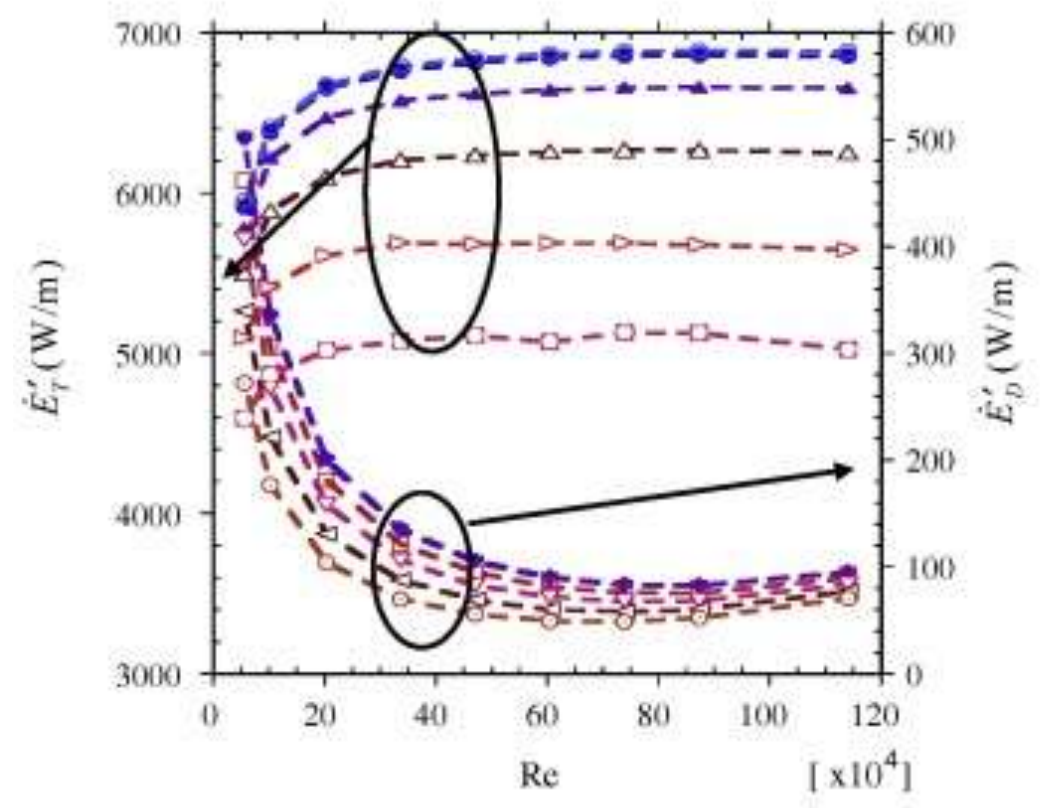

(b)

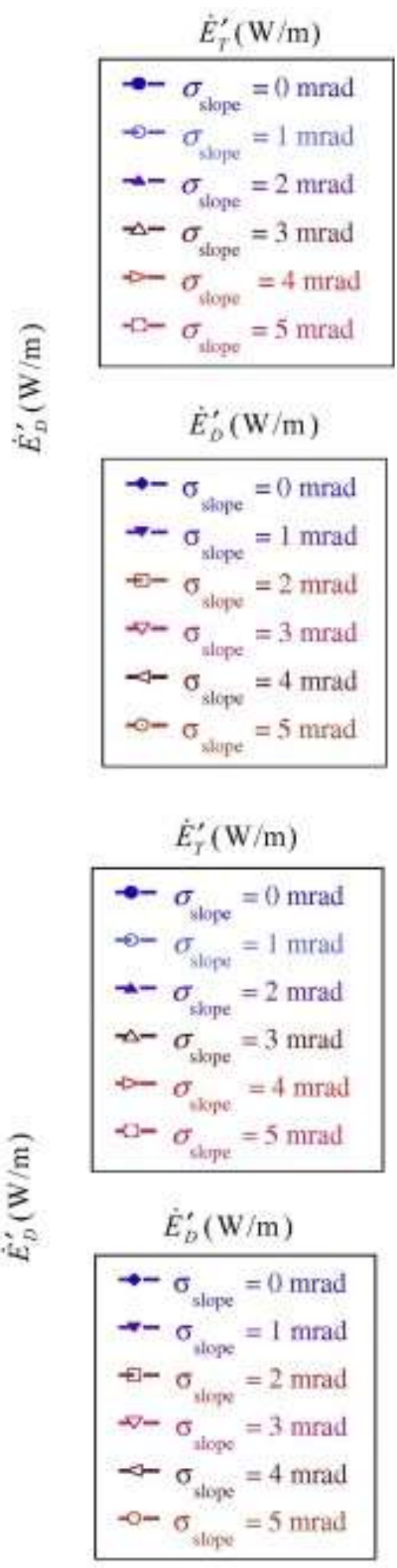

Fig. 20 Exergy flow rate and exergy destruction rate in a receiver as a function of Reynolds number and slope errors at a specularity error of 0 mrad: (a) $600 \mathrm{~K}$ and (b) $650 \mathrm{~K}$ 
$\mathrm{K}$, respectively. The variation of the exergy destruction rate has the same trend as that of the entropy generation rate as expected, since the ambient temperature $\left(T_{o}\right)$ is fixed. The exergy destruction rate decreases as the slope error increases due to reduced irreversibilities and thus entropy generation rates as the slope error increases as discussed above. Despite the decrease in the exergy destruction rate with increasing slope errors, the exergy flow rate (available energy) is shown to significantly decrease as the slope errors increase. Thus, even though, the entropy generation rates reduce as the slope errors increase, the energy delivered to the receiver also reduces significantly as most of the rays will not be intercepted by the receiver and thus lower available energy. The reduction in energy delivered to the receiver as the slope errors increase is much more than the reduction in entropy generation rates as the slope errors increase. Clearly, the presence of slope errors degrades the exergetic performance of the receiver, except for the slope error of $1 \mathrm{mrad}$, where the exergy flow rate is almost similar to that at $0 \mathrm{mrad}$.

\section{Conclusion}

This paper presents results of the influence of slope errors and specularity errors on the optical, thermal and thermodynamic performance of a parabolic trough system. From the study, results showed that the presence of slope errors significantly influences the heat flux distribution on the receiver's absorber tube and subsequently the thermal and thermodynamic performance of the receiver. The peak heat flux is shown to reduce as the slope errors increase. It was also shown that specularity errors do not significantly affect the heat flux distribution on the receiver's absorber tube, especially for values of the specularity error less than 3 mrad. From the study, the intercept factor was found to reduce by up to $21 \%$ as the slope errors increased from 0 mrad to 5 mrad and by up to $5 \%$ as specularity errors increased from $0 \mathrm{mrad}$ to values above $4 \mathrm{mrad}$. 
Furthermore, the overall thermal efficiency was shown to reduce significantly as the slope errors increased. The reduction in the overall thermal efficiency was about $16 \%-17 \%$ as the slope error increased from 0 to $5 \mathrm{mrad}$ for all values of specularity errors at any given temperature or Reynolds number. The influence of the specularity error on the thermal efficiency was shown to be insignificant at values of the specularity error lower than 4 mrad.

A comparison of the thermal performance under different absorber tube heat flux distributions showed that using a uniform heat flux profile over estimates the thermal performance by about $13 \%$ while using concentrated heat flux on the absorber tube's lower half and a direct normal radiation on the receiver's upper half under predicts performance by about $7 \%$.

From the thermodynamic analysis, it was shown that although the entropy generation rates reduce as slope errors increase, the receiver exergetic performance significantly reduces as slope errors increase. Therefore, the presence of slope errors significantly degraded both the thermal and thermodynamic performance of a parabolic trough receiver.

\section{Acknowledgements}

The support received from the University of the Witwatersrand, Johannesburg, Tshwane University of Technology, the University of Pretoria and the University of Cape Town is duly acknowledged and appreciated. This funding received from the National Research Foundation (NRF) is also duly acknowledged and appreciated. Special acknowledgement to the anonymous reviewers for their constructive suggestions that helped improve the quality of this paper. 


\section{REFERENCES}

ANSYS, 2014a. ANSYS® Academic research, release 14.5, ANSYS FLUENT user's guide, ANSYS, Inc.

ANSYS, 2014b. ANSYS® Academic research, release 14.5, ANSYS FLUENT, theory guide, ANSYS, Inc.

Bakos, G.C., 2006. Design and construction of a two-axis Sun tracking system for parabolic trough collector (PTC) efficiency improvement. Renewable Energy 31, 2411-2421.

Balghouthi, M., Ali, A.B.H., Trabelsi, S.E., Guizani, A., 2014. Optical and thermal evaluations of a medium temperature parabolic trough solar collector used in a cooling installation. Energy Conversion and Management 86, 1134-1146.

Bartelmeß, L., Monte, C., Adibekyan, A., Sohr, O., Ottermann, C., Korb, T., Hollandt, J., 2014. Characterization of high temperature solar thermal selective absorber coatings at operation temperature. Energy Procedia 49, 2070-2079.

Bendt, P., Rabl, A., Gaul, H.W., Reed, K.A., September 1979. Optical analysis and optimization of line-focus solar collectors. Solar Energy Research Institute, Golden, CO, SERI/TR 34-092, 164.

Burkholder, F., Kutscher, C., 2009. Heat loss testing of Schott's 2008 PTR70 parabolic trough receiver. NREL Technical Report, NREL/TP - 550-45633, 1-58.

Burkholder, F., Kutscher, C., 2008. Heat-loss testing of Solel's UVAC3 parabolic trough receiver. NREL Technical Report, NREL/TP - 550-42394, 1-19.

Cheng, Z.D., He, Y.L., Cui, F.Q., Xu, R.J., Tao, Y.B., 2012. Numerical simulation of a parabolic trough solar collector with nonuniform solar flux conditions by coupling FVM and MCRT method. Sol Energy 86, 1770-1784.

Dow, 2012. Syltherm800 heat transfer fluid: product technical data. http://www.dow.com/heattrans/products/synthetic/syltherm.htm [Last accessed 10.12.2014].

Dudley, E.V., Kolb, J.G., Mahoney, A.R., Mancini, T., R., Sloan, M., Kearney, D., 1994. Test results: SEGS LS-2 solar collector. Sandia National Laboratory Report, SAND94-1884.

Duffie, J.A., Beckman, W.A., 2006. Solar Engineering of Thermal Processes, 3 ed. John Wiley and Sons Inc., Hoboken, New Jersey.

Eck, M., Steinmann, W., 2002. Direct steam generation in parabolic troughs: First results of the DISS project. Journal of Solar Energy Engineering 124, 134-139. 
Fernández-García, A., Zarza, E., Valenzuela, L., Pérez, M., 2010. Parabolic-trough solar collectors and their applications. Renew Sust Energ Rev 14, 1695-1721.

Forristall, R., October 2003. Heat transfer analysis and modeling of a parabolic trough solar receiver implemented in Engineering Equation solver. NRELTechnical Report, NREL/TP-550$34169,1-145$.

García-Cortés, S., Bello-García, A., Ordóñez, C., 2012. Estimating intercept factor of a parabolic solar trough collector with new supporting structure using off-the-shelf photogrammetric equipment. Appl. Energy 92, 815-821.

Gaul, H., Rabl, A., 1980. Incidence-angle modifier and average optical efficiency of parabolic trough collectors. Transaction of ASME, Journal of Solar Energy Engineering 102, 535-550.

Gee, R., Brost, R., Zhu, G., Jorgensen, G., 2010. An improved method for characterizing reflector specularity for parabolic trough concentrators. In Proceedings of Solar PACES Conference, Perpignan (France), 21-24 ${ }^{\text {th }}$ September, 2010, 1-8.

Güven, H.M., Bannerot, R.B., 1986. Determination of error tolerances for the optical design of parabolic troughs for developing countries. Solar Energy 36, 535-550.

He, Y., Xiao, J., Cheng, Z., Tao, Y., 2011. A MCRT and FVM coupled simulation method for energy conversion process in parabolic trough solar collector. Renew Energ 36, 976-985.

Hoste, G., Schuknecht, N., 2015. Thermal efficiency analysis of SkyFuel's advanced, largeaperture, parabolic trough collector. Energy Procedia 69, 96-105.

IEA, 2014. Technology roadmap: Solar thermal electricity. 2014 Edition, 1-46.

IRENA Working paper, June 2012. Renewable energy technologies: Cost analysis seriesConcentrating solar power. 1: Power sector, 1-41.

Jeter, S.M., 1987. Analytical determination of the optical performance of practical parabolic trough collectors from design data. Sol Energy 39, 11-21.

Jeter, S.M., 1986. Calculation of the concentrated flux density distribution in parabolic trough collectors by a semifinite formulation. Solar Energy 37, 335-345.

Kalogirou, S., 2009. Solar Energy Engineering: Processes and Systems, 1 ed. Elsevier, Academic Press, Oxford, UK.

Kalogirou, S.A., 2004. Solar thermal collectors and applications. Prog Energ Combust 30, 231295.

Kock, F., Herwig, H., 2005. Entropy production calculation for turbulent shear flows and their implementation in cfd codes. Int J Heat Fluid Fl 26, 672-680. 
Kock, F., Herwig, H., 2004. Local entropy production in turbulent shear flows: a high-Reynolds number model with wall functions. Int J Heat Mass Trans 47, 2205-2215.

Le Roux, W.G., Bello-Ochende, T., Meyer, J.P., 2014. The efficiency of an open-cavity tubular solar receiver for a small-scale solar thermal Brayton cycle. Energy Conversion and Management 84, 457-470.

Lee, H., 2014. The geometric-optics relation between surface slope error and reflected ray error in solar concentrators. Solar Energy 101, 299-307.

Lei, D., Li, Q., Wang, Z., Li, J., Li, J., 2013. An experimental study of thermal characterization of parabolic trough receivers. Energy Conversion and Management 69, 107-115.

Li, M., Wang, L.L., 2006. Investigation of evacuated tube heated by solar trough concentrating system. Energy Conversion and Management 47, 3591-3601.

Lu, J., Ding, J., Yang, J., Yang, X., 2013. Nonuniform heat transfer model and performance of parabolic trough solar receiver. Energy 59, 666-675.

Lüpfert, E., Riffelmann, K., Price, H., Burkholder, F., Moss, T., 2008. Experimental analysis of overall thermal properties of parabolic trough receivers. Sol Energy Eng 130, 021007.

Maccari, A., Montecchi, M., 2007. An optical profilometer for the characterisation of parabolic trough solar concentrators. Solar Energy 81, 185-194.

Marif, Y., Benmoussa, H., Bouguettaia, H., Belhadj, M.M., Zerrouki, M., 2014. Numerical simulation of solar parabolic trough collector performance in the Algeria Saharan region. Energy Conversion and Management 85, 521-529.

Mokheimer, E.M.A., Dabwan, Y.N., Habib, M.A., Said, S.A.M., Al-Sulaiman, F.A., 2014. Techno-economic performance analysis of parabolic trough collector in Dhahran, Saudi Arabia. Energy Conversion and Management 86, 622-633.

Mullick, S.C., Nanda, S.K., 1989. An improved technique for computing the heat loss factor of a tubular absorber. Solar Energy 42, 1-7.

Muñoz, J., Abánades, A., 2011. Analysis of internal helically finned tubes for parabolic trough design by CFD tools. Appl Energy 88, 4139-4149.

Mwesigye, A., Bello-Ochende, T., Meyer, J.P., 2016. Heat transfer and entropy generation in a parabolic trough receiver with wall-detached twisted tape inserts. International Journal of Thermal Sciences 99, 238-257.

Mwesigye, A., Bello-Ochende, T., Meyer, J.P., 2014a. Heat transfer and thermodynamic performance of a parabolic trough receiver with centrally placed perforated plate inserts. Appl. Energy 136, 989-1003. 
Mwesigye, A., Bello-Ochende, T., Meyer, J.P., 2014b. Minimum entropy generation due to heat transfer and fluid friction in a parabolic trough receiver with non-uniform heat flux at different rim angles and concentration ratios. Energy 73, 606-617.

Peng, S., Hong, H., Jin, H., Zhang, Z., 2013. A new rotatable-axis tracking solar parabolictrough collector for solar-hybrid coal-fired power plants. Solar Energy 98, Part C, 492-502.

SolTrace, 2012. SolTrace optical modelling software. SolTrace 2012.7.9.

Ouagued, M., Khellaf, A., Loukarfi, L., 2013. Estimation of the temperature, heat gain and heat loss by solar parabolic trough collector under Algerian climate using different thermal oils. Energy Conversion and Management 75, 191-201.

Philibert, C., Frankl, P., 2010. International Energy Agency, Technology roadmap: Concentrating solar power. IEA/OECD, Paris, France.

Pottler, K., Ulmer, S., Lüpfert, E., Landmann, M., Röger, M., Prahl, C., 2014. Ensuring performance by geometric quality control and specifications for parabolic trough solar fields. Energy Procedia 49, 2170-2179.

Price, H., Kearney, D., January, 1999. Parabolic-trough technology roadmap: A pathway for sustained commercial development and deployment of parabolic trough technology. NREL Technical Report, NREL/TP-550-24748, 1-35.

Price, H., Lüpfert, E., Kearney, D., Zarza, E., Cohen, G., Gee, R., Mahoney, R., 2002. Advances in parabolic trough solar power technology. Sol Energy Eng 124, 109-125.

PSA, 2016. Plataforma Solar de Almeria. http://www.psa.es/en/instalaciones/parabolicos.php. [Last accessed [12.02.2016].

Richter, C., Teske, S., Short, R., 2009. Concentrating solar power. Greenpeace/SolarPACES/ESTELA Global outlook 09, 1-86.

Schott, 2016. Schott PTR®70 receivers. http://www.schott.com/csp/english/schott-solar-ptr-70receivers.html. [Last accessed 15.06.2015]

Shih, T., Liou, W.W., Shabbir, A., Yang, Z., Zhu, J., 1995. A new k-€ eddy viscosity model for high reynolds number turbulent flows. Comput. Fluids 24, 227-238.

Skouri, S., Ben Salah, M., Bouadila, S., Balghouthi, M., Ben Nasrallah, S., 2013. Optical, geometric and thermal study for solar parabolic concentrator efficiency improvement under Tunisia environment: A case study. Energy Conversion and Management 75, 366-373.

Swinbank, W.C., 1963. Long-wave radiation from clear skies. Q. J. R. Meteorol. Soc. 89, 339348. 
Thomas, A., Guven, H.M., 1994. Effect of optical errors on flux distribution around the absorber tube of a parabolic trough concentrator. Energy Conversion and Management 35, 575-582.

Wang, P., Liu, D.Y., Xu, C., 2013. Numerical study of heat transfer enhancement in the receiver tube of direct steam generation with parabolic trough by inserting metal foams. Appl. Energy $102,449-460$.

Wendelin, T., 2006. Parabolic trough VSHOT optical characterization in 2005-2006. Presented at the parabolic trough technology workshop, Incline Village, Nevada, $14^{\text {th }}-16^{\text {th }}$ February, NREL/PR-550-40024.

Xiao, X., Zhang, P., Shao, D.D., Li, M., 2014. Experimental and numerical heat transfer analysis of a V-cavity absorber for linear parabolic trough solar collector. Energy Conversion and Management 86, 49-59.

Xu, Q., Li, L., Li, H., Huang, W., Li, Y., 2014. Performance comparison of solar parabolic trough system with glass and film reflector. Energy Conversion and Management 85, 581-590.

Yang, B., Zhao, J., Xu, T., Zhu, Q., 2010. Calculation of the concentrated flux density distribution in parabolic trough solar concentrators by Monte Carlo ray-trace method. In: Proceedings of Symposium on Photonics and Optoelectronic (SOPO), Chengdu, China, 19 ${ }^{\text {th }}$ $21^{\text {st }}$ June, 1-4.

Yılmaz, İH. Söylemez, M.S., 2014. Thermo-mathematical modeling of parabolic trough collector. Energy Conversion and Management 88, 768-784. 